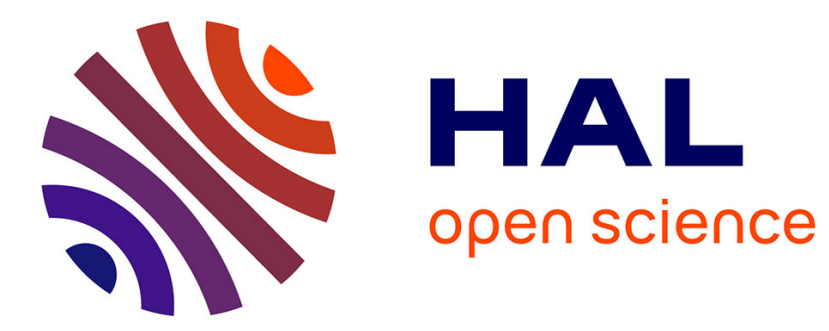

\title{
Point-record incentives, asymmetric information and dynamic data
}

\author{
Jean Pinquet, Georges Dionne, Charles Vanasse, Mathieu Maurice
}

\section{To cite this version:}

Jean Pinquet, Georges Dionne, Charles Vanasse, Mathieu Maurice. Point-record incentives, asymmetric information and dynamic data. 2007. hal-00243056

\section{HAL Id: hal-00243056 https://hal.science/hal-00243056}

Preprint submitted on 6 Feb 2008

HAL is a multi-disciplinary open access archive for the deposit and dissemination of scientific research documents, whether they are published or not. The documents may come from teaching and research institutions in France or abroad, or from public or private research centers.
L'archive ouverte pluridisciplinaire HAL, est destinée au dépôt et à la diffusion de documents scientifiques de niveau recherche, publiés ou non, émanant des établissements d'enseignement et de recherche français ou étrangers, des laboratoires publics ou privés. 


\title{
ECOLE POLYTECHNIQUE
}

Point-record incentives, asymmetric information and dynamic data

\author{
Jean Pinquet \\ Georges Dionne \\ Charles Vanasse \\ Mathieu Maurice
}

Juin 2007

Cahier $n^{\circ} 2007-10$

\section{LABORATOIRE D'ECONOMETRIE}

1 rue Descartes F-75005 Paris

(33) 155558215

http://ceco.polytechnique.fr/

mailto:lyza.racon@shs.poly.polytechnique.fr 


\title{
Point-record incentives, asymmetric information and dynamic data ${ }^{1}$
}

\author{
Jean Pinquet ${ }^{2}$ \\ Georges Dionne ${ }^{3}$ \\ Charles Vanasse ${ }^{4}$ \\ Mathieu Maurice ${ }^{5}$
}

Juin 2007

\section{Cahier $n^{\circ} 2007-10$}

Résumé: Les politiques de sécurité routière utilisent souvent des mécanismes incitatifs basés sur les infractions pour améliorer le comportement des conducteurs. Ces mécanismes sont soit monétaires (amendes, primes d'assurance), soit non monétaires (permis à points). Nous utilisons des données québécoises couvrant une période allant de 1983 à 1996 pour analyser l'efficacité incitative de ces mécanismes. Nous analysons leurs propriétés théoriques par rapport au nombre de points associés aux infractions et par rapport au temps contrat. Ces propriétés sont ensuite testées empiriquement. Nous comparons l'efficacité globale des différents mécanismes incitatifs et nous relions les résultats obtenus avec les propriétés de la relation entre l'effort de conduite prudente et le risque d'infractions. Nous concluons à la présence d'aléa moral dans les données. Par ailleurs, la prime indicée sur les points introduite en 1992 a réduit de $15 \%$ la fréquence d'infractions.

Abstract: Road safety policies often use incentive mechanisms based on traffic violations to promote safe driving. These mechanisms are both monetary (fines, insurance premiums) and non-monetary (point-record driving licenses). We use Quebec data collected between 1983 and 1996 to analyze the efficiency of these mechanisms in reducing the effects of asymmetric information. We derive the theoretical properties of the incentive mechanisms with respect to contract time and accumulated demerit points. These properties are then tested empirically. We compare the overall efficiency of the different incentive schemes and try to link global results with the theoretical properties of the relation between safe driving effort and traffic violation risk. We do not reject the presence of moral hazard in the data. Moreover, the experience rating premium introduced in 1992 did reduce the frequency of traffic violations by $15 \%$.

Mots clés : Mécanismes incitatifs, permis à points, sécurité routière

Key Words : Point-record mechanisms, incentive effects, road safety

Classification JEL: D81, C23

\footnotetext{
${ }^{1}$ Claire Boisvert improved significantly the presentation of the manuscript.

${ }^{2}$ Université Paris 10 et Ecole Polytechnique (courriel: jean.pinquet@polytechnique.edu)

${ }^{3}$ HEC Montréal (courriel: dionne@hec.ca)

${ }^{4}$ TD Asset Management

${ }^{5}$ HEC Montréal
} 


\section{Introduction}

Since the seventies fatality rates due to road-traffic accidents have decreased steadily in developed countries, although risk exposure increased at the same time (see OECD, 2005). This situation stands in sharp contrast to that in less developed regions, especially emerging economies. For example, the road fatality rate decreased by forty percent in France during the last ten years, whereas it was multiplied by five in Vietnam. ${ }^{1}$ As of 2004, the average number of fatalities per 100,000 persons was equal to 20 at the world level. This number is always lower for OECD countries and higher for emerging countries. ${ }^{2}$ The implied social cost is very heavy, even in developed countries (Doyle, 2005). By 2020, road-traffic accidents should become the third cause of the disability-adjusted life years lost from disease or injury worldwide (Murray and Lopez, 1997). The corresponding rank was equal to nine in 1990.

The discrepancy between economic regions with respect to the social costs of road-traffic accidents can be explained by many factors. For instance, the "Haddon matrix" (Haddon, 1968) provides a multifactorial approach to road safety, in which human, vehicle, and environment factors are crossed with three phases (before, during and after the accident). All the factors clearly play in favor of the most developed countries. A major reason for the improvement of the situation in the OECD has been the development of incentives for safe driving. Experience rating schemes used by the insurance industry have incentive properties (see Boyer and Dionne, 1989; Abbring et al, 2003). They are supplemented by point-record driving licenses based on traffic violations. In many countries, each convicted traffic offense is filed with a specific number of demerit points. When the accumulated number of points exceeds a given threshold, the driving license is suspended. Redemption clauses are added so that this penalty can be avoided in the long run. ${ }^{3}$ Bourgeon and Picard (2007) investigate the most desirable features of point-record licenses in terms of road safety incentives and discuss how they can be combined with fines to design an optimal system that internalizes the social cost of road accidents. They do not take into account insurance pricing based on traffic violations.

A point-record driving license was implemented in Quebec in 1978, together with a no-fault insurance regime for bodily injuries which replaced a tort system. The 
North American continent preceded Europe in the design of such systems. Pointrecord driving licenses were introduced in 1947 in the USA. By comparison, they were introduced in Germany, France, and Spain in 1974, 1992 and 2005, respectively.

Increases in premiums are often triggered by claims at fault in the motor insurance sector. No-fault environments are however common in the North American continent, and traffic violations are in consequence events likely to be used in experience rating schemes. ${ }^{4}$ In Quebec, the Société de l'Assurance Automobile $d u$ Quebec (referred to as SAAQ in what follows) is a public monopoly which provides coverage for bodily injury. The SAAQ is also in charge of accident prevention and control, which includes the management of driving licenses. Before 1992, the rating structure for bodily injury insurance was completely flat. The public authorities in Quebec decided to implement an experience rating scheme based on accumulated demerit points, a reform applied from December 1, 1992 onwards. This mechanism was added to other incentives, i.e. fines, the point-record driving license in force since 1978, and the private sector insurance pricing scheme for property damage.

The purpose of this paper is to analyse the incentive properties of both pointrecord driving license and insurance pricing based on traffic violations. Using data from 1983 to 1996, we want to compare theoretical results to empirical findings obtained from SAAQ policies. Section 2 reviews the recent literature on asymmetric information and road safety. Section 3 presents the data base and the first empirical results related to the introduction of the new pricing policy implemented in 1992. The point-record mechanisms (driving license and insurance pricing) are described in Section 4 and their incentive properties are investigated in a continuous-time model of optimal behavior that extends the previous literature significantly. These results are then confronted with empirical findings. Identifiability issues created by unobserved heterogeneity are addressed in Section 5. Section 6 presents empirical evidence on the incentive properties of the two point-record mechanisms. In the spirit of Abbring et al (2003), we propose a means of disentangling unobserved heterogeneity from incentive effects in a duration model. It involves including an actuarial predictor as an offset variable in the hazard function. The incentives created by the threat of driving 
license suspension are found to increase with accumulated demerit points and to decrease with the seniority of the last traffic offense, if any. These findings confirm the theoretical analysis. Additionally, we find that driving license suspension spells reduce accident and traffic offense risks. A possible explanation is that the perceived driving utility of drivers increases after a driving license suspension spell.

The experience rating system implemented in 1992 substantially reduced traffic violations among all drivers, whatever their incentive level. Lastly, we compare the overall efficiency of the different incentive schemes, and try to link global results to theoretical properties of the relation between safe driving effort and traffic violation risk. Conclusions are drawn in Section 7 and technicalities are relegated to an appendix.

\section{Literature review on asymmetric information and road safety}

Studies on incentive mechanisms for road safety have been discussed in the economic literature for many years (Peltzman, 1975; Landes, 1982; Graham and Garber, 1984; Boyer and Dionne, 1987; Blomquist, 1988). Many mechanisms have been proposed. Those most relevant to our purpose are fines, point-record driving licences, and insurance experience rating. In the last mentioned case, the individual driving history is summarized by past accidents or by point-records based on traffic offenses.

In the presence of asymmetric information, insurers use partial insurance or experience rating to improve resource allocation. Both schemes have been proved to be efficient for handling moral hazard and adverse selection (see Shavell, 1979; Rothschild and Stiglitz, 1976, for partial insurance, and Chiappori et al, 1994; Dionne and Lasserre, 1985, for experience rating). Different empirical tests have been proposed to measure the efficiency of such mechanisms for road safety (Sloan et al, 1995; Boyer and Dionne, 1989) or to measure the presence of residual asymmetric information problems in insurers' portfolios (Chiappori and Salanié, 2000; Dionne, Gouriéroux and Vanasse, 2001). More recently, Abbring, Chiappori and Pinquet (2003) designed a new test based on the dynamics of in- 
surance contracts to detect the presence of residual moral hazard. Their model makes it possible to separate the moral hazard effect on accidents from unobserved heterogeneity. They found no evidence of moral hazard in the French car insurance market ${ }^{5}$. Their approach consists in analysing the behavior of policyholders in the studied insurance setting and contrasting this behavior with that predicted by theoretical models under moral hazard and adverse selection. Both problems can be identified from a detailed analysis of the data. Accidents change the schedule of future premiums and incentives for road safety. Individuals that accumulate accidents are charged higher premiums and, under moral hazard, should improve their driving behavior and reduce their risk to retrieve their original premium. So a negative correlation should be observed between past accidents and future accidents under moral hazard. The empirical test is not so simple, however, since it involves the distinction between pure heterogeneity and state dependence.

Insurance pricing may not be sufficient as a tool for designing an optimal road safety policy since it may not create the appropriate incentives for reckless drivers (Sloan et al, 1995). Bourgeon and Picard (2007) show how point-record driving licence suspensions provide incentives for road safety among normal drivers in presence of failures in the judicial system or in the insurance market to provide optimal incentives. Point-record driving licences also allow the government to incapacitate reckless drivers. Fines for traffic violations (as insurance pricing) may be ineffective for reckless drivers when their amounts are bounded above, either because some drivers would not be able to pay them or for some equity reasons (see also Shavell, 1987). However, fines (as insurance pricing) do reinforce the efficiency of the point record mechanism by providing more incentives to normal drivers. It must be emphasized that, in their model with only two levels of prevention, the optimal fine must be fixed at its maximal level and must be neither progressive nor regressive. Finally they discuss the optimality of redeeming mechanisms as a screening device.

Public intervention can also be justified when there is a significant difference between the private and the social cost of human lives (Viscusi, 1993). Finally, drivers may be poorly informed on their own accident or infraction probabilities or may misunderstand some features of the incentive environment. 
The economic environment we shall study in the next sections contains many common characteristics discussed above as well as differences that will be important for the analysis and interpretation of the results with respect to the presence of moral hazard in the data. Regarding Abbring et al (2003), the insurance pricing scheme is not the major incentive scheme in this study but is a complementary tool to the point-record driving licence. The commitment environment is about the same as well as the wealth effect which is rather weak. However, the pricing scheme of the Quebec public automobile insurance is not strictly increasing and convex with respect to past demerit points but is increasing by steps.

With respect to the theoretical contribution of Bourgeon and Picard (2007), we shall test the prediction that point-record driving licence is efficient for road safety under moral hazard. We shall also study the complementary aspect of fines by considering some particularities of the public insurance pricing based on past convictions as a progressive fine based on traffic offenses history. It can also be interpreted as a malus scheme without the bonus counterpart.

\section{Presentation of the data base and prelimi- nary empirical results}

Our data base represents roughly one percent of the SAAQ portfolio. The panel covers the period from January 1, 1983 to December 31, 1996. A first sample of 40,000 license holders was selected at random at the beginning of 1983. Then about 300 young drivers were added each following year. ${ }^{6}$ Leaving the motor insurance market is the only cause of attrition from the data base. The attrition rate per year is close to $1.5 \%$, which is very low as compared to the private sector. ${ }^{7}$ This attrition result is obviously explained by the monopolistic position of the SAAQ. Moreover, endogenous attrition is not very high, and can be estimated from a bivariate probit model on traffic offenses and departures from the sample. A score test for the nullity of the correlation coefficient between the two equations ${ }^{8}$ was performed with the regression components set used in Section 6. The null hypothesis was not rejected at a five percent significance level. 
For each driver, we have the personal characteristics available on the driving license for the current period. They are used as regression components in the empirical study. Several types of events are recorded in the data base; they are listed below with related variables in addition to the date.

- Accidents which have led to a police report. Only those with bodily injury are compensated by the SAAQ.

- Convicted violations of the Road Safety Code, together with the number of demerit points which are used in the point-record mechanisms. The number of demerit points is related to the severity of the traffic violation. Their distribution is given in Section 4.4.

- Driving license suspensions, which are spells rather than events.

- The premium payments which are related to accumulated demerit points since the 1992 reform. They are made every two years on the policyholder's birthday.

The yearly frequencies of accidents with bodily injuries, accidents of all types (not including jointly-agreed reports to private insurers) and traffic violations are equal to, respectively, $1.4 \%, 6.7 \%$ and $16.9 \%$ on average between 1985 and 1996. Figure 1 represents the relative frequencies derived from a one year moving average. $^{9}$

\section{Insert Figure 1 about here}

There is an overall decline in the frequency of accidents, whereas the frequency of traffic violations remains more stationary. This may seem surprising, but it is explained by the evolution of the traffic control environment. For instance, the number of traffic control devices such as radars increased during the eighties and nineties. An increase in the rate of traffic offenses recorded by devices or police officers among those committed explains this relationship. Figure 1 shows evidence of several periods where the frequency of traffic violations increased along with opposite variations in the frequencies of accidents. An increase in the intensity of traffic control during these periods may well explain such observations. 
A traffic violation committed by a driver must be selected twice in order to be filed with demerit points. First, it must be recorded by a control device or a police officer. We already mentioned that the related selection rate increased in the past. Second, the recorded traffic violation must be convicted. Now the attribution of demerit points is somewhat discretionary. After the 1992 reform for instance, people are being forced to pay more in premiums given demerit points, and we might expect policemen to be more hesitant to hand them out, and to give warnings instead. ${ }^{10}$ We think however that the second selection rate is less likely to vary with time than the first one.

A downturn is also observed in Figure 1 for the frequency of traffic violations just before the date (December 1, 1992) of the reform which introduced the experience rating structure based on demerit points. Notice that the reform was announced four months before its enforcement, which may explain this lag. ${ }^{11}$ On average, the annual frequency of traffic violations was equal to $17.6 \%$ before the reform and $15.4 \%$ afterwards, which corresponds to a $12.5 \%$ decrease. The 1992 reform can be interpreted as a laboratory experiment to test whether an exogenous change in the use of memory reduces traffic violations. But the lower rate of traffic violations following the 1992 Quebec reform may be due to the change of other factors that may influence the driver behavior. Identifying the influence of these factors necessitates a control group that is not affected by the policy change. Unfortunately, we do not have access to such a control group since the insurer is a monopoly. In Section 6.2, we will link the average decrease in traffic violation frequency before and after the 1992 reform to the overall efficiency of the different incentive schemes (i.e. fines, point-record driving license and insurance premium).

As monetary and non monetary incentives to safe driving are based on demerit points, the optimal behavior models designed in Section 4 link safe driving effort and traffic violation risk. However the social cost of road traffic is caused by accidents. To reconcile these two approaches, let us mention two results. First, demerit points are good predictors of accidents. This is well documented in the literature and is confirmed on our data in Section 6.1. Second, the global stationarity of convicted traffic violations frequency observed in Figure 1 coexists with a probable decrease in the frequency of committed traffic violations (see 
the aforementioned developments on selection rates). Lowering traffic violation risk through point-record mechanisms should also lower accident risk and the related social cost.

Finally, we observe in Figure 1 that accidents with bodily injuries evolve in much the same way as all those recorded in the SAAQ file. We include accidents of all types in the empirical analysis in order to obtain more stable results. ${ }^{12}$

\section{Incentive effects of point-record mechanisms}

\subsection{Point-record mechanisms in Quebec}

In this section, we describe Quebec's point-record mechanisms which are derived from traffic violations, both monetary (insurance premiums) and non-monetary (point-record driving license). Comparisons are given with respect to mechanisms used by other countries. Then we investigate their incentive properties. In many countries nowadays driving license suspensions are based on demerit points. In Quebec, demerit points are assigned to convictions for traffic offenses and their numbers depend on the traffic violation severity. If the accumulated number of demerit points reaches or exceeds a given threshold, the driving license is suspended. Before January 1990 this threshold was equal to twelve in Quebec and has been equal to fifteen since then.

In order to mitigate the social cost of driving license suspension, redeeming systems exist in most real-world point-record driving licenses. In Quebec, the demerit points related to a given driving offense are redeemed after two years. Hence, driving license suspensions will depend on the demerit points recorded during the last two years. The French system is similar, with a duration of three years and a twelve point threshold. New York State follows the same logic as Quebec and France (with an eighteen month seniority for the redemption of offenses and an eleven point threshold).

The average number of demerit points per convicted offense is equal to 2.4 in Quebec (a distribution is given in Section 4.4). Hence a license suspension is very unlikely with the average frequency of traffic violations. But heterogeneity of risks is high and a point-record driving licence is also an incapacitating device of risky and reckless drivers through the licence suspensions. 
Another redeeming system consists in cancelling all the demerit points after a given period of violation-free driving. This mechanism was recently implemented in Spain, with a two year period. ${ }^{13}$ Utah has a point-record driving license similar to the Spanish one.

The experience rating structure introduced by the SAAQ in December 1, 1992 links each premium paid every two years to the demerit points accumulated over the previous two years. The rating structure is given in Section 4.4. Once the premium is paid, the driver is reinstated with a fresh zero point record. Thus the length of the record relevant to the derivation of optimal behavior never exceeds two years.

\subsection{Basic model for a point-record driving license with- out redemption}

Bourgeon and Picard (2007) analyze the incentive effects of point-record driving licenses for normal drivers. Their model uses a binary effort variable. They also examine features such as redeeming mechanisms or probationary licenses. We extend their approach with a continuous effort level. Hence the efficiency of effort may also be a continuous function of contract time, a desirable property for empirical validation. The basic model described in this section shows that the careful driving effort exerted by a rational policyholder increases with the number of accumulated demerit points under fairly general conditions.

We suppose that the driving license is revoked when the driver reaches a total of $N$ demerit points. For the sake of simplicity, each convicted traffic violation is linked to one supplementary demerit point in this section. ${ }^{14} \mathrm{~A}$ driver with a suspended driving license is reinstated after a period $D$ with a fresh zero-point record like that of a beginner. ${ }^{15}$ The duration $D$ may be fixed or random in the model. In Quebec, a licence suspension is of random length because drivers must pass a new exam after a given period before recovering their driving license. A rational driver maximizes an expected lifetime utility expressed in $\$$ and derived from:

- An instantaneous driving utility, $d_{u}$.

- A time-dependent disutility of effort, which we denote as $e(t) .{ }^{16}$ This effort 
level is linked to an instantaneous traffic violation frequency risk, denoted as $\lambda(e(t))$. The hazard function $\lambda$ is assumed to be a positive, decreasing and strictly convex function of the effort level. The utility flow $d_{u}-e(t)$ is continuously discounted at an interest rate denoted by $r$.

In this section, we suppose that there is no redeeming mechanism. In that case, the lifetime expected utility (we assume an infinite horizon) depends only on the number of accumulated demerit points, which we denote as $n$. The Bellman equation on the expected utility

$u_{n}=\max _{e \geq 0}\left(d_{u}-e\right) d t+\left(\exp (-r d t) \times\left[\left((1-\lambda(e) d t) \times u_{n}\right)+\left(\lambda(e) d t \times u_{n+1}\right)+o(d t)\right]\right)$

leads to

$$
u_{n}=\frac{d_{u}}{r}-\frac{\lambda_{*}\left(u_{n}-u_{n+1}\right)}{r},(0 \leq n<N),
$$

where

$$
\lambda_{*}(\Delta u) \underset{\text { def }}{=} \min _{e \geq 0} e+[\lambda(e) \times \Delta u] .
$$

In equation (2), $\Delta u$ is the lifetime utility loss between the current state and the one reached after a supplementary traffic offense, and $e+[\lambda(e) \times \Delta u]$ is the disutility flow of both effort and the corresponding lifetime utility loss.

The function $\lambda_{*}$ is the dual of the hazard function $\lambda$ (see Rockafellar, 1996, and Appendix A.1 for more details and for proofs of the results that follow). All the $u_{n}$ are lower than $u_{\max }=d_{u} / r$, which is the private lifetime driving utility without the point-record driving license. Equation (1) means that $\lambda_{*}\left(u_{n}-\right.$ $\left.u_{n+1}\right) / r$ is the minimal private utility cost of the point-record mechanism for a driver with $n$ demerit points.

If the private disutility of driving license suspension is only the loss of driving utility during a period $D$, we have that

$$
u_{N}=\beta u_{0}, \beta=E[\exp (-r D)] .
$$

We consider that $u_{N}$ is the lifetime expected utility just after the suspension of the driving license. The utilities are then derived from the recurrence equations (1) and (3).

Optimal effort depends on the variation of lifetime utility as it minimizes the function defined in equation (2). Hence optimal effort depends on the number 
of accumulated demerit points, but not on time in this setting. We denote the optimal effort associated with $n$ demerit points as $e_{n}$. We have that

$$
e_{n}>0 \Leftrightarrow u_{n}-u_{n+1}>\frac{-1}{\lambda^{\prime}(0)} \text {. }
$$

Besides, it is shown in Appendix A.1 that $e_{n}$ increases with $n$ for any given value of $N$.

Fines represent another monetary incentive scheme applied in Quebec during the whole period investigated in this study. Let us denote $\overline{f a}$ as the average fine for a traffic violation conviction. Since fines and premiums are low in comparison to average wealth, we leave out risk aversion. With fines, equation (4) becomes

$$
e_{n}>0 \Leftrightarrow u_{n}-u_{n+1}+\overline{f a}>\frac{-1}{\lambda^{\prime}(0)}
$$

Fines by themselves do not deter drivers from using their cars if $d_{u}>\lambda_{*}(\overline{f a})$. If fines are combined with the preceding point-record driving license, the optimal effort still increases with $n$ for a given value of the average fine. The incentives are effective for every value of $n$ if $\overline{f a}>-1 / \lambda^{\prime}(0)$. The optimal effort also increases with the average fine for any given values of $n$ and $N$ (see Appendix A.1, Figures 4a, 4b). This result will be used in the interpretation of the incentive effects observed for the 1992 reform.

\subsection{Models for point-record driving licenses with redemp- tion}

In Quebec, each traffic violation is redeemed at the end of a two year period. Integrating this feature to the optimal behavior model is difficult, as all the seniorities of non-redeemed driving offenses must be included as state variables in the dynamic programming equations. Another redeeming system consists in cancelling all the demerit points after violation-free driving of a given duration, say T. Such mechanisms are also enforced in the real world (see Section 4.1). An optimal behavior model is easier to design in this framework since only the seniority of the last convicted driving offense must be added to the number of demerit points accumulated as a state variable. Later on, we will denote the 
latter redeeming mechanisms as of Type I, and the Quebec-like systems as of Type II.

The model of the preceding section can be extended to a Type I redeeming system (see Appendix A.2). The conclusions are the following.

- For every given number of demerit points, optimal effort increases continuously with time. If optimal effort is greater than zero, it is strictly increasing.

- When all the demerit points are redeemed (i.e. after a violation-free driving record of duration $T$ ), the effort collapses to the minimum level.

- Effort variation after a convicted driving offense may be positive or negative. If the last traffic violation immediately follows another one, the variation is positive, but decreases with the duration between the two last offenses. A drop in the effort level is expected if the duration is large enough.

The time-effect of point-record driving licenses on optimal driving behavior is very different with a Type II redeeming system like the one in Quebec. We do not have rigorous proofs to provide in that intricate framework, but we use the preceding results to guess the main qualitative properties of Type II redeeming mechanisms.

For both types, lifetime utility is expected to increase with time for a given number of demerit points accumulated. However the link between utility and effort is different according to the type. Optimal effort depends on the difference between the present utility and a substitute utility (i.e. that reached after an additional traffic violation). With a Type I mechanism, the substitute utility only depends on the number of demerit points accumulated as the time variable is reset to zero after a traffic violation. Hence we obtain an increasing link between time and effort. With a Type II redeeming system, all the seniorities of past traffic violations are kept as state variables after an additional traffic violation, and the substitute utility increases with time as the present utility. Time should have more value for worse situations, hence the substitute utility should increase faster than the present utility. Thus optimal effort should decrease with time. 
Besides, we prove in Appendix A.2 that optimal effort is continuous before and after a redemption, a property which does not hold for a type I mechanism. This property will be tested empirically in Section 6.1. Optimal effort is then expected to increase at each traffic violation in order to compensate the decreasing link between time and effort. On the whole, the incentive properties of a Type II system are closer to those of a mechanism without redemption than to those of a Type I system.

\subsection{Incentive effects of premiums indexed on demerit points: The example of Quebec}

Table 1 presents the rating structure which was enforced for each driving license on the first contract birthday following December 1, 1992. The premium paid every two years after this date depends on the accumulated demerit points in the last two years. It does not represent the total premium for bodily injury insurance but the additional premium related to demerit points.

\section{Insert Table 1 about here}

In this section, the incentive properties of this rating structure are analysed separately from the point-record driving license. An important input is the distribution of demerit points for a given driving offense, which we left out in the preceding sections. Denoting $f_{j}$ as the proportion of traffic violations with $j$ demerit points, we have the following values

$$
f_{1}=4.71 \% ; f_{2}=52.32 \% ; f_{3}=38.34 \% ; f_{4}=2.83 \% ; f_{5}=1.80 \% .
$$

Note that $f_{5}$ actually refers to offenses with five points and more. From Table 1, we see that the premium is a step function of the accumulated demerit points. Because of the local non convexity of the premium, the incentives may not always increase with the number of demerit points accumulated. Let us consider for instance a policyholder just before her contract birthday. The incentive level will be stronger with two accumulated demerit points than with four. With four points, it is indeed less than likely that the next traffic offense will trigger an increase in premium. The corresponding probability is $2.83+1.80=4.63 \%$, if we assume that the distribution of the $f_{j}$ is independent of the accumulated 
demerit points. The incentives to safe driving are stronger at a two point level because the probability of climbing a step in the rating structure after a traffic offense is close to one. The aforementioned result stands in contrast to the one obtained by Abbring et al (2003) for the French "bonus-malus" scheme, which has an exponential structure.

Let us design an optimal behavior model based on this rating structure. Once the premium is paid, the driver is reinstated with a fresh zero point record. Hence the optimal control model can be designed with the next contract birthday as the horizon. ${ }^{17}$

We denote the premium paid for a $n$ point record as $\pi_{n}$. We discard here the point-record driving license and its incentive implications. As a consequence, the driving utility is no longer a parameter, as there is no licence deprivation. On the other hand, we retain fines in the incentives to safe driving. We denote $v_{n}(t)$ as the optimal expected disutility until the next contract birthday, where $t$ is the seniority of the last birthday and $n$ is the number of demerit points accumulated since that date. We have the terminal conditions

$$
v_{n}(T)=\pi_{n}, \forall n=0, \ldots, N
$$

The values of $n$ greater than $N$ (the threshold that triggers license suspension) are absorbed by $N$ in what follows. With the notations of Section 4.2, the Bellman equation is the following

$$
v_{n}^{\prime}(t)=r v_{n}(t)-\lambda_{*}\left(\overline{f a}+\Delta v_{n}(t)\right),(0 \leq n \leq N),
$$

with

$$
\Delta v_{n}(t)=\left(\sum_{j / f_{j}>0} f_{j} v_{\min (n+j, N)}(t)\right)-v_{n}(t) .
$$

The expected variation of the optimal disutility after a traffic offense is denoted as $\Delta v_{n}(t)$. It is added to the average fine in the argument of $\lambda_{*}$, which determines the optimal effort level. Figure 2 provides examples of functions $\Delta v_{n}$ with the following assumptions:

$$
\begin{gathered}
r=0.1 ; \lambda(e)=\lambda(0) \times \exp (-\alpha e), \lambda(0)=0.22, \\
-1 / \lambda^{\prime}(0)=\$ 100 \Leftrightarrow \alpha=1 / 22 .
\end{gathered}
$$




\section{Insert Figure 2 about here}

In equation (8), the parameter $-1 / \lambda^{\prime}(0)$ is the threshold on the argument of $\lambda_{*}$ beyond which the incentives are effective (see equation (4) in the context of point-record driving licences). We retained a value lower than the average fine of $\$ 130$ in Quebec, so that the incentives are effective at every level. The $\left(\Delta v_{n}\right)_{n=0,2,4}$ functions in Figure 2 are plotted with respect to $t$. A global average $\Delta v(t)=\sum_{n=0}^{n=N-1} p_{n}(t) \Delta v_{n}(t)$ is also plotted, where $p_{n}(t)$ is the probability that a driver with the risk level $\lambda(0)$ and the behavioral parameter $\alpha$ given in equation (8) obtains $n$ demerit points at date $t$. The average traffic violation frequency including optimal effort is equal to 0.155 , which is close to the average value given after the reform in Section 3.

From Figure 2, we observe that:

- Most of the functions $\Delta v_{n}$ decrease with contract-time, which entails the same property for optimal effort. The average does increase however because the demerit point distribution shifts with time towards higher values.

- Some functions $\Delta v_{n}$ can also increase with contract-time, which is the case for $n=2$ in this example.

- Figure 2 also shows that the incentives with two points are stronger than with four points whatever the seniority of the last contract birthday. Hence effort is not always an increasing function of the number of demerit points accumulated, a result which was already mentioned for contracts close to their next birthday.

- Lastly, note that $\Delta v_{4} \geq \Delta v_{0}$, which if explained by a global convexity of the premium schedule. Indeed, the increases in premium are equal to $\$ 50$ at the first step and to $\$ 74$ at the second step (see Table 1).

The overall average of $\Delta v_{n}(t)$ with respect to $t$ and $n$ is close to $\$ 12$ in this example. This value depends on the individual parameters $r$ and $\Delta u$. However this is not the case for the terminal values $\Delta v_{n}(T)$, and Figure 2 shows that the average of $\Delta v_{n}(t)$ with respect to $n$ does not vary much with time. The values $\Delta v_{n}(t)$ are added to the average value of fines in the argument of $\lambda_{*}$, 
which determines the incentive level. In Section 6.2, this nine percent increase on average with respect to $\$ 130$ will be compared with the variation of traffic violation frequency before and after the reform.

Solving a holistic incentive model (i.e. one which includes fines, premium and the point-record driving license) is beyond the scope of this paper. The corresponding Bellman equation is given in Appendix A.4. To summarize, the optimal effort levels related to fines, point-record driving license and experience rated premium analysed separately are constant, increasing on average and non monotonic functions of the accumulated demerit points. We shall test these relationships in the following sections.

\section{Description and indentification issues on count data in insurance}

Frequency risk models in insurance are addressed at length by the actuarial literature. Actuarial models use mixtures of Poisson models to describe the dynamics of the data. Their main limitation is that identification issues are not taken into account of, since the observed dynamics are supposed to be created only by the revelation of unobserved heterogeneity. If random effects are timeindependent, the predictor which summarizes the individual history (the "bonusmalus" coefficient) decreases with risk exposure (bonus) and increases with the number of events (malus). Consider for instance a mixture of Poisson processes with a hazard function $\lambda_{i}$ for policyholder $i$. The multiplicative random effect $\varepsilon_{i}$ verifies $E\left(\varepsilon_{i}\right)=1 ; V\left(\varepsilon_{i}\right)=\sigma^{2}$. Actuarial predictors are based on expectations of the type $E\left(\varepsilon_{i} \mid N_{i, t}\right)$, where $N_{i, t}$ is the number of insurance claims made by policyholder $i$ between 0 and $t$. The standard formula for the "bonus-malus" coefficient is

$$
E\left(\varepsilon_{i} \mid N_{i, t}\right)=\frac{1+\left(\sigma^{2} \times N_{i, t}\right)}{1+\left(\sigma^{2} \times \Lambda_{i, t}\right)}, \Lambda_{i, t}=E\left(N_{i, t}\right)=\int_{0}^{t} \lambda_{i}(s) d s .
$$

This formula reflects the continuous time-effect of the revelation of unobserved heterogeneity on one hand. On the other hand, there is a jump of the predictor at each event occurrence. It is valid if $\varepsilon_{i}$ follows a Gamma distribution (Dionne, Vanasse, 1989), or in a semiparametric setting, with a linearity constraint on 
the shape of the predictor. This is known as the "linear credibility" approach (Bühlmann, 1967). The hazard function which integrates experience rating is then equal to $\lambda_{i}(t) \times E\left(\varepsilon_{i} \mid N_{i, t}\right)$. If the time-independence assumption of the random effects is relaxed, the autocorrelation coefficients of a stationary distribution usually decrease with the lag. This means that the predictive ability of events decreases with their seniority (see Pinquet et al, 2001). The continuous time-effect of risk revelation is different in this case. The "no-claim discount" is lower for a claimless history than with the basic actuarial model, but stronger since the last claim, if any. In this case indeed, the continuous aging of past claims supplements the increase in risk exposure.

Disentangling incentive effects from unobserved heterogeneity is an identification issue. The basic strategy is to obtain statistics which are invariant with respect to the mixing distribution related to hidden features in the risk distribution. Abbring et al (2003) provide an inference strategy if the hazard function is multiplied by a constant $\beta$ after each event (accident for instance) and does not vary with time. Assessing the existence of moral hazard amounts to estimating $\beta$ and testing for $\beta<1$ if the marginal benefit of effort increases with the number of claims.

Time effects do however exist in the point-record mechanisms in force in Quebec, so we cannot apply this approach here. In Section 4.3, we showed that safe driving effort induced by the point-record driving license increases with the number of demerit points and decreases with time if this number is greater than zero. The induced duration-event effects on traffic violation risk are at the opposite of those created by the revelation of unobserved heterogeneity. A basic empirical result in non-life insurance is that empirical hazard functions related to frequency risks increase with claims and decrease with time. This justifies the "bonus-malus" systems and means that incentive effects do not outweigh the revelation effect on this type of data. ${ }^{18}$ 


\section{Empirical results on the incentive effects of point-record mechanisms}

\subsection{Point-record driving license}

In this section, we analyze the data before the 1992 reform which introduced the experience rating scheme based on demerit points. Thus the point-record driving license interacts only with fines. Regressions are performed from January 1985 (we need a two year history to derive the accumulated demerit points) to December 1992, date of the reform enforcement. We will try to obtain a confirmation of the theoretical findings of Sections 4.2 and 4.3 (i.e. the effort level globally increases with the accumulated demerit points and decreases with the seniority of non redeemed traffic violations, if any), and to confirm the presence of moral hazard in the data.

The whole history of traffic violations is useful in assessing the revelation of unobserved heterogeneity, whereas the last two years are enough to determine the incentive level. The hazard functions of convicted traffic offenses and accidents are estimated with a proportional hazards model (Cox, 1972). We retained the following specification

$$
\lambda_{i}^{j}(t)=\exp \left(x_{i}(t) \beta_{j}\right) \times g_{j}\left(c d p_{i}(t)\right) \times k_{j}\left(n s p s_{i}(t)\right) \times B M_{i}^{j}(m(t)) \times h_{j}^{S_{i}(t)}\left(c_{i}(t)\right) .
$$

In equation (10), $\lambda_{i}^{j}(t)$ is the hazard function of type $j(j=1$ : traffic violation or $j=2$ : accident) for driver $i$ at calendar time $t$. Regression components which do not refer to the individual driver record are denoted by the line-vector $x_{i}(t)$. We retained the gender, driving license class, place of residence, age of the driver and calendar effects related to years and months. ${ }^{19}$ The number of demerit points accumulated in the last two years is denoted as $c d p_{i}(t)$, and a decreasing shape is expected for $g_{1}$ from the theoretical model of Sections 4.2 and 4.3. The variable $n s p s_{i}(t)$ is the number of past driving license suspension spells. The link with traffic violation risk should be decreasing if such a spell increases the perceived driving utility.

The revelation of unobserved heterogeneity is taken into account by an actuarial predictor denoted as $B M_{i}^{j}(m(t))$, which is included as a constant in the hazard function (an "offset" variable). This predictor is updated each month, and $m(t)$ 
is the month related to $t$. We retained a dynamic random effects specification, and the prediction takes into account the seniority of past traffic violations as well as their number and the license holder risk exposure. The derivation of bonus-malus coefficients follows the linear credibility approach (see Section 5) and is given in Appendix A.5 in a context of dynamic random effects.

Effort is expected to decrease with time only if the number of demerit points accumulated is greater than zero. Hence we specified a stratified proportional hazards model. ${ }^{20}$ The baseline hazard functions $h_{j}^{S_{i}(t)}$ depend on the risk type $j$ and on the stratum $S_{i}(t)$. There are two strata levels, depending on whether the variable $c d p_{i}(t)$ is equal to zero or not.

Lastly, contract time $c_{i}(t)$ is integrated into the baseline hazard function $h_{j}$. The function $c_{i}$ is set equal to zero at the beginning of the whole period. Then it is reset to zero at each event which triggers a variation of the accumulated demerit points (i.e. traffic violation or redemption). This event-driven operation should eliminate interactions between calendar and contract-time effects for the stratum associated to strictly positive values of accumulated demerit points.

In equation (10), the actuarial predictor is assumed to reflect the revelation of unobserved heterogeneity in the first place, whereas the functions $g_{j}(c d p)$ and $h_{j}^{S}$ are first related to the event and time effects of incentives. We do not, however, pretend to disentangle exactly the revelation of unobserved heterogeneity and incentives effects with this specification because the actuarial predictor is calibrated on the observed dynamics, which include the incentive effects. Let us clarify two points.

- The actuarial predictor reflects the observed dynamics of the data, where hazard rates increase with traffic violations and decrease with time. This entails an opposite effect in the estimation of the functions $g_{j}(c d p)$ and $h_{j}$.

- Some particular specifications of the individual hazard functions can be identified beyond the distribution mixing created by unobserved heterogeneity. For instance, this is the case if the hazard function varies geometrically with the number of past events and does not depend on time, as shown in Abbring et al (2003). We are not aware of a general solution capable of eliminating the event and time effect of unobserved heterogeneity. 
The actuarial predictor is derived from estimated covariances between dynamic random effects related to both traffic violation and accident equations (see Appendix A.5).

\section{Insert Table 2 about here}

Table 2 exhibits a decreasing shape with the lag for both covariances series. This means that the predictive ability of past traffic violations on both risk types decreases with the seniority. The two moments related to a zero lag can be interpreted as the relative increase in traffic violation risk after an event (traffic violation or accident, depending on the equation) if risk exposure is close to zero. The intuition can be grasped from equation (9). For instance, the bonus-malus coefficient for traffic violation risk doubles after a traffic violation at least in the beginning. The corresponding increase for accident risk is equal to $63 \%$ and justifies the use of traffic violations in insurance rating from an actuarial equity point of view.

\section{Insert Table 3 about here}

From the theoretical model of Section 4.3, we expect effort to increase with the number of demerit points accumulated, under moral hazard. This is globally true from Table 3, as coefficients linked to this variable decrease after seven points for traffic violation risk. It is worth mentioning that the SAAQ warns the policyholders when the accumulated demerit points reach a seven point threshold. On the other hand, the drivers are not informed when offenses are redeemed.

The license suspension threshold increased in January 1990 from twelve to fifteen points. We tested the effect of this reform and did not obtain significant differences in the results. For instance, effort increases beyond seven points before and after the 1990 reform.

The number of past driving license suspension spells brings interesting results on the traffic violation equation. One suspension spell entails a $5.6 \%$ reduction in traffic violation frequency, and two a $13.1 \%$ reduction. A possible explanation is that the perceived driving utility of drivers increases after a driving licence suspension spell. 


\section{Insert Figure 3 about here}

Let us comment on the baseline hazard functions given in Figure 3 on traffic violation risk. Consider first the stratum with $c d p>0$. Contract-time is less than two years as it represents the time elapsed since the last variation of accumulated demerit points. The hazard function is globally increasing. This result which is consistent with the prediction of the theoretical model (i.e. optimal effort decreases with the seniority of non redeemed traffic violations, if any). The other baseline hazard function is not exactly stationary whereas it should be since it is related to drivers with zero demerit points. This means that the effect on the hazard function of the actuarial coefficient included as an offset variable is probably too strong. However the global variations of the hazard functions in the two strata are very different (62\% vs. 12\%), which reflects a significant difference in the time effects of incentives.

Let us test another prediction of the theoretical model, which is the continuity of effort before and after a redemption. If a traffic violation is followed by a two year violation free record, the baseline hazard function jumps from 1.62 (the terminal value of the baseline hazard function related to $c d p>0$ ) to 1.60 , which corresponds to the initial value of the other hazard function. On the other hand, the actuarial predictor is continuous before and after a redemption. Hence the continuity property of effort is almost fulfilled.

From Table 2, we know that the bonus-malus coefficient for traffic violation risk doubles after a traffic violation if risk exposure is low. This explains why the baseline hazard function of the stratum defined by $c d p=0$ is higher than the other one. When a traffic violation is recorded, the only modification in the related risk is due to the modification of the incentives. Hence the decrease in the baseline hazard function compensates the increase in the actuarial coefficient.

If the actuarial coefficient is not included as an offset variable in the proportional hazards regression, the baseline functions for traffic violation risk decrease with time, whatever the number of demerit points accumulated. This means that the time effect of unobserved heterogeneity is higher than the time effect of incentives.

From Table 3, the number of demerit points accumulated has less influence on accident risk than on traffic violation risk. A possible interpretation is that we 
cannot separate at fault from no-fault accidents. In the literature, the incentive effect is usually higher with at fault accidents. Besides, drivers close to license suspension might also have an opportunistic behavior with respect to traffic violations (e.g. paying more attention to radars) without modifying otherwise their attitude towards road traffic risk.

As with traffic violations, past driving license suspension spells reduce accident risk. The baseline hazard functions related to accidents are more stationary.

\subsection{Incentive effects of the experience rating scheme in force since 1992 and overall comparisons}

In Section 3, we mentioned a $12.5 \%$ decrease in the average frequency of traffic violations before and after the reform which introduced the experience rating structure based on demerit points. This result is scarcely modified if we control with the regression components used in Table 3. A regression estimated on the whole period (i.e. from 1985 to 1996) with the covariates of Section 6.1 and a dummy related to the period following December 1, 1992 associates the reform with a $15 \%$ decrease. $^{21}$

Figure 2 suggests that the number of demerit points accumulated since the last contract birthday should be able to discriminate the effort level. For instance, drivers with no traffic violation since this date are less incited by the reform to drive safely than those with two demerit points accumulated. We did not, however, obtain significant results with this variable (i.e. by crossing the dummy linked to the 1992 reform and the number of demerit points accumulated since the last contract birthday). The actual incentive effect of the reform is similar to a uniform increase in the average fine. ${ }^{22}$

Let us make an overall comparison of the three incentive schemes. Before the 1992 reform, fines were supplemented by a point-record driving license. Optimal effort after $n$ non redeemed traffic violations depends on the argument of $\lambda_{*}$, which is the dual of the hazard function $\lambda$ (see equation (2)). This argument is equal to $\overline{f a}+u_{n}-u_{n+1}$ from equation (5). We recall that the average fine $\overline{f a}$ is equal to $\$ 130$. Besides, the 1992 reform entails an average increase in the argument of $\lambda_{*}$ which is equal to $\$ 12$ from Section $4.4 .{ }^{23}$ At this point, it seems interesting to relate the optimal risk level and the argument of $\lambda_{*}$, which 
determines the optimal effort level.

This relation can be assessed from the elasticity between optimal frequency risk and the argument of $\lambda_{*}$. When the incentives are effective, it can be shown that this elasticity is greater than -1 if and only if $\log (\lambda)$ is a convex function of effort (elasticity and convexity are considered locally: see Appendix A.4 for a proof). A global elasticity equal to -1 is linked to an exponential decay of $\lambda$. With $\lambda(e)=$ $\lambda(0) \times \exp (-\alpha e)$ indeed, the optimal risk level as a function of $\Delta u$ (the argument of $\left.\lambda_{*}\right)$ is equal to $1 /(\alpha \Delta u)$ if the incentives are effective. Lastly, incentives are locally more efficient if the elasticity is less than -1 , which corresponds to a locally concave shape for $\log (\lambda)$. From Table 3, a traffic violation worth two or three points entails a reduction of traffic violation frequency of about twenty percent beyond seven demerit points accumulated. A twenty percent reduction in the frequency of traffic violations could be related to a twenty five percent increase in the argument of $\lambda_{*}$ with an exponential effort function.

Let us assess the global efficiency of the 1992 reform. A fifteen percent reduction in traffic violation risk can be related to the variation in the argument of $\lambda_{*}$ induced by the reform if the incentives are effective. As the reform entailed a significant reduction in traffic violation risk for every number of demerit points accumulated, we can assume that incentives are effective for a representative driver before the 1992 reform. From equation (5), a sufficient condition to have this result is that the average fine is higher than the threshold beyond which the incentives are effective.

Effective incentives lead us to analyse the elasticity between traffic violation risk and the argument of $\lambda_{*}$. Suppose that we leave out the modifications of lifetime utility variations due to the aggregation of incentive schemes. Then we can relate:

- On one hand, a relative increase in the argument of $\lambda_{*}$ which lies between $9 \%$ and $10 \%$. Indeed, the 1992 reform entails a $\$ 12$ average increase in the argument of $\lambda_{*}$. This increase supplements the other arguments of $\lambda_{*}$, i.e. the $\$ 130$ average fine and the utility variation for the point-record driving license. In Table 3, the point-record driving license offers significant incentives to careful driving beyond a seven point threshold, which corresponds to a minority of drivers (1.4\%). The contribution of the point- 
record driving license to the argument of $\lambda_{*}$ is low as compared with fines, and the $\$ 12$ increase corresponds to a relative increase in the argument which lies between $9 \%$ and $10 \%$.

- On the other hand, a $15 \%$ reduction in the frequency of traffic violations after the 1992 reform.

This suggests that the elasticity between the optimal frequency risk and the argument of $\lambda_{*}$ is less than -1 in this case. This result is linked to a locally concave shape of $\log (\lambda)$ for the representative driver. However external effects could also explain the reduction in the frequency of traffic violations. We cannot eliminate these effects because there is no control group that is not affected by the reform. Obviously, the last developments were obtained at the expense of several approximations, but the purpose was to provide a helicopter view of the incentive schemes as a whole.

\section{Conclusion}

As a conclusion, let us compare the three incentive mechanisms used by the SAAQ. Fines are the most efficient device on average, but the absence of memory entails a uniform incentive effect for given characteristics of the policyholder. We designed our incentive models with a representative driver, but there is of course heterogeneity in the individual parameters, such as the threshold beyond which the incentives are effective. We did not have wealth variables at hand, and an interesting empirical issue would have been to cross such variables with a reform dummy in risk assessment.

The experience rated premium enforced in 1992 is a monetary point-record mechanism. Its incentive effects do not strictly increase with the accumulated demerit points because of the steps in the rating structure. The empirical results exhibit a rather uniform efficiency of the reform, i.e. a $15 \%$ decrease in the frequency of traffic violations. The incentive effect of the reform looks more like that induced by an increase in the average fine. The SAAQ is going to modify its rating policy, with a premium increase from the first demerit point. This will enhance its efficiency for the majority of drivers with a violation-free record. 
The incentive effects of the point-record driving license increase with the number of demerit points accumulated. This confirms the presence of moral hazard in the data. The point-record driving license also acts as an incapacitating device for reckless drivers. Another desirable property is the fact that the behavior of risky drivers improves when they come close to or go beyond the license suspension threshold, as was shown in Section 6.1.

\section{Notes}

${ }^{1}$ See WHO (2004). The fatality rates include pedestrians, motorcyclists and bicyclists involved in road accidents. The discrepancy in fatality rates between OECD and emerging countries cannot be explained by variations in risk exposure alone. For instance, motor vehicles used in Vietnam are mostly motorcycles. The number of motorcycles grew by $29 \%$ during 2001. At the same time road fatalities rose by $37 \%$.

${ }^{2}$ As of 2004, this number was equal to 5 in Holland, 8.6 in Canada, 9.2 in France and 14.5 in the USA. On the other hand, 27 fatalities per 100,000 persons were reported in Vietnam.

${ }^{3}$ These clauses and their incentive properties are detailed in Section 4.

${ }^{4}$ Real-life experience rating schemes have a "crime and punishment" flavor which makes it difficult to use no-fault claims. Traffic violations also have a predictive ability for accident risks (see Section 6). Besides, they are often accessible to American insurance companies (Federal Driver's Privacy Protection Act, 1997), which is not the case in European countries like France.

${ }^{5}$ Other references on empirical analyses of asymmetric information in insurance markets include Cohen (2005), Dionne and St Michel (1991), Finkelstein and McGarry (2006), Puelz and Snow (1994).

${ }^{6}$ Selecting at random one percent of the new licence holders every year would of course have been a preferable sampling procedure. One thousand new licence holders would then have been selected every year as the entry rate in the SAAQ portfolio is close to $2.5 \%$.

${ }^{7}$ The attrition rate usually ranges between five and ten percent for mutual insurers, and is closer to twenty percent for stock insurers. The aforementioned values are given for a single product, i.e. motor insurance. The turnover rate can rise to fifty percent in situations where the contract is not tacitly renewed, as in United Kingdom.

${ }^{8}$ Binary variables related to traffic offenses and attrition were created on a monthly basis, and explained with the covariates used in Section 6.1. The score test statistic is equal to 0.34. Hence we do not reject the nullity of the correlation coefficient at usual significance levels.

${ }^{9}$ We begin in 1985 in order to match the regressions which follow, as a two year history is needed to derive the accumulated demerit points. Data are here averaged over one year, which is necessary because of the strong seasonal effects. 
${ }^{10}$ We thank a referee for suggesting this interpretation.

${ }^{11}$ Drivers with a contract birthday between the announcement of the reform and its enforcement are not incited by the experience rated premium before the birthday. Incentives exist otherwise (for these drivers after the birthday, and for all the other drivers). A referee suggested using this natural experiment in order to disentangle the incentive effects of the reform from calendar effects. We did not obtain significant results. Four months are however a short period, and only one driver out of twelve was not incited by the rating scheme on average during the period.

${ }^{12}$ Important variables in the regressions like the accumulated demerit points have low frequencies for the highest values. An accurate estimation is difficult if the frequency of events is low, as it is the case for accidents with bodily injuries.

${ }^{13}$ These redemptive mechanisms also exist in experience rating schemes. In the French "bonus-malus" system, drivers with a bad accident record are rated as beginners after a two year claimless history.

${ }^{14}$ All the traffic offenses recorded in the data base are linked to convictions, which is the condition for the addition of demerit points.

${ }^{15}$ This reinstatement can be seen as a redemption of demerit points. In the paper, we consider a redemptive mechanism to be a suppression of demerit points applied before the suspension of the driving license.

${ }^{16}$ Safe driving effort can also reduce the expected disutility of accidents. If $e \rightarrow \delta(e)$ is the implied decrease in the disutility flow, replacing $e$ by $e-\delta(e)$ includes the influence of safe driving effort on accident risk. This effect should not be significant when insurance coverage is compulsory and almost comprehensive as in Quebec for bodily injury. The accident risk is low in compulsory insurance regimes such as the one in Quebec for bodily injury.

${ }^{17}$ This is another important difference between the SAAQ experience rating scheme and the French "bonus-malus" system. The horizon of utility derivation is that of the next premium payment, which is much shorter than a suitable horizon for the French "bonus-malus" scheme.

${ }^{18}$ This point could be questioned because incentive effects are intrinsic, which is not the case for unobserved heterogeneity (which is residual with respect to observable information). The domination of the revelation effect does however hold in practice. On the other hand, incentives effects can have the same duration-event effects as unobserved heterogeneity. This is the case for Type I redemptive systems, from the results given in Section 4.3.

${ }^{19}$ Comprehensive regressions based on two year periods can be found in Dionne, Maurice, Pinquet, and Vanasse (2001).

${ }^{20}$ Stratification in a proportional hazards model means that Cox likelihoods (of a multinomial logit type) are derived for each stratum and then multiplied together. In other words, an individual with an observed event is assumed to have competed only with other individuals in the same stratum and at risk at the same date. However, the same coefficients for the covariates are used across all strata.

${ }^{21}$ We retained the covariates used in Table 3, except for dummies related to years and the 
number of past license suspension spells. The estimated additive parameter for the reform dummy is equal to -0.163 , and the related standard deviation is equal to 0.008 . Hence the reform effect is conclusive with the usual tests significance levels.

${ }^{22}$ In Section 4.2 indeed, we mentioned that the optimal effort increases with the average fine for every number of demerit points accumulated if road safety incentives are a mix of fines and of a point-record driving license.

${ }^{23}$ In Section 4.4, we derived expected disutilities $v_{n}(t)$ until the next contract birthday. They can be associated with a negative lifetime utility $u_{n}(t)$. We have

$$
u_{n}(t)=-v_{n}(t)+\exp (-r(T-t)) u_{0}(0) ; \quad u_{0}(0)=\frac{-v_{0}(0)}{1-\exp (-r T)} .
$$

From the preceding equation, we have $u_{n}(t)-u_{n+1}(t)=v_{n+1}(t)-v_{n}(t)$. The average increase in disutility after a traffic offense is equal to the corresponding decrease in lifetime utility. 
TABLE 1:-SAAQ INSURANCE PREMIUMS FOR BODILY INJURY AS A FUNCTION OF ACCUMULATED DEMERIE POINTS SINCE THE LAST CONTRACT BIRTHDAY

\begin{tabular}{ccc}
\hline \hline $\begin{array}{c}\text { Accumulated demerit points } \\
\text { (last two years) }\end{array}$ & $\begin{array}{c}\text { Premium for the next } \\
\text { two years (Canadian \$) }\end{array}$ & $\begin{array}{c}\text { Frequency } \\
\text { (\%) }\end{array}$ \\
\hline $0,1,2,3$ & 50 & 93.7 \\
$4,5,6,7$ & 100 & 4.9 \\
$8,9,10,11$ & 174 & 1.1 \\
$12,13,14$ & 286 & 0.2 \\
15 and more & 398 & 0.1 \\
\hline
\end{tabular}


TABLE 2.--ESTIMATED MOMENTS OF RANDOM EFFECTS USED IN THE PREDICTION

\begin{tabular}{ccc}
\hline \hline & $\widehat{\operatorname{Cov}}\left(\varepsilon_{i, t}^{1}, \varepsilon_{i, t-h}^{1}\right)$ & $\widehat{\operatorname{Cov}}\left(\varepsilon_{i, t}^{2}, \varepsilon_{i, t-h}^{1}\right)$ \\
\hline$h=0$ & 0.981 & 0.636 \\
$h=1$ & 0.800 & 0.482 \\
$h=2$ & 0.745 & 0.368 \\
$h=3$ & 0.731 & 0.336 \\
$h=4$ & 0.704 & 0.344 \\
$h=5$ & 0.705 & 0.293 \\
$h=6$ & 0.648 & 0.289 \\
$h=7$ & 0.673 & 0.288 \\
$h=8$ & 0.636 & 0.342 \\
$h=9$ & 0.608 & 0.296 \\
\hline
\end{tabular}

$\varepsilon_{i, t}^{j}$ : Multiplicative random effect for driver $i$, in period $t$, and risk of type $j$. Random effects are supposed stationary and i.i.d. between the individuals. The covariances reflect the predictive ability of a traffic violation on both frequency risk types. They are estimated from an unconstrained semiparametric approach. We used Poisson regressions on traffic violations and accidents. Data are observed from 1983 to 1992, and we retained the covariates denoted as $\mathrm{x}$ in equation (10). The decreasing shape of the covariances as functions of the lag means that the predictive abilities of the traffic violations decrease with their seniority. 
TABLE 3.-ESTIMATION OF THE HAZARD FUNCTION FOR TRAFFIC VIOLATION AND ACCIDENT FREQUENCY RISKS

\begin{tabular}{|c|c|c|c|c|}
\hline Variable & Level & Frequency (\%) & Traffic violation risk & Accident risk \\
\hline \multirow{7}{*}{$\begin{array}{c}\text { nsps: } \\
\text { Number of past } \\
\text { driving license } \\
\text { suspension spells }\end{array}$} & $0(*)$ & 98.96 & 0 & 0 \\
\hline & 1 & 0.94 & -0.058 & -0.064 \\
\hline & & & $(0.022)$ & $(0.046)$ \\
\hline & 2 & 0.09 & -0.140 & -0.519 \\
\hline & & & $(0.062)$ & $(0.168)$ \\
\hline & 3 and more & 0.01 & -0.091 & -0.147 \\
\hline & & & $(0.156)$ & $(0.410)$ \\
\hline \multirow{26}{*}{$\begin{array}{c}\text { cdp: } \\
\text { Number of demerit } \\
\text { points } \\
\text { accumulated } \\
\text { (last two years) }\end{array}$} & 0 point & 76.60 & stratum & stratum \\
\hline & 1 point $(*)$ & 0.39 & 0 & 0 \\
\hline & 2 points & 9.36 & 0.100 & 0.073 \\
\hline & & & $(0.060)$ & $(0.107)$ \\
\hline & 3 points & 6.23 & 0.119 & 0.192 \\
\hline & & & $(0.061)$ & $(0.107)$ \\
\hline & 4 points & 1.92 & 0.124 & 0.065 \\
\hline & & & $(0.062)$ & $(0.111)$ \\
\hline & 5 points & 2.09 & 0.155 & 0.121 \\
\hline & & & $(0.062)$ & $(0.110)$ \\
\hline & 6 points & 1.25 & 0.104 & 0.120 \\
\hline & & & $(0.063)$ & $(0.113)$ \\
\hline & 7 points & 0.72 & 0.102 & 0.005 \\
\hline & & & $(0.065)$ & $(0.118)$ \\
\hline & 8 points & 0.55 & -0.032 & 0.101 \\
\hline & & & $(0.067)$ & $(0.120)$ \\
\hline & 9 points & 0.43 & -0.133 & 0.152 \\
\hline & & & $(0.071)$ & $(0.125)$ \\
\hline & 10 points & 0.32 & -0.184 & 0.084 \\
\hline & & & $(0.072)$ & $(0.127)$ \\
\hline & 11 points & 0.06 & -0.051 & -0.192 \\
\hline & & & $(0.104)$ & $(0.223)$ \\
\hline & 12 points & 0.04 & -0.625 & 0.087 \\
\hline & & & $(0.147)$ & $(0.230)$ \\
\hline & $13-14$ points & 0.04 & -0.283 & -0.347 \\
\hline & & & $(0.120)$ & $(0.265)$ \\
\hline
\end{tabular}

(*): Reference level. Additive coefficients, level frequencies are weighted by duration. Standard errors are in parentheses. Additional regression variables are: gender, driving license class (9 levels), place of residence (16 levels), age of the driver (5 slopes) as well as calendar effects related to years (8 levels) and months (12 levels).

Number of observations: 3,587,654 duration-events of at most one month, derived from 41,290 driving licenses. Global test for the nullity of coefficients (traffic violations): likelihood ratio statistic $=19416.71$,; degrees of freedom $=62$; limit significance level $<0.0001$.

Global test for the nullity of coefficients (accidents): likelihood ratio statistic $=4464.91$; degrees of freedom $=62$; limit significance level $<0.0001$. 
Figure 1.-- Relative frequencies (in percentage) for traffic violations and accidents (one year moving average)

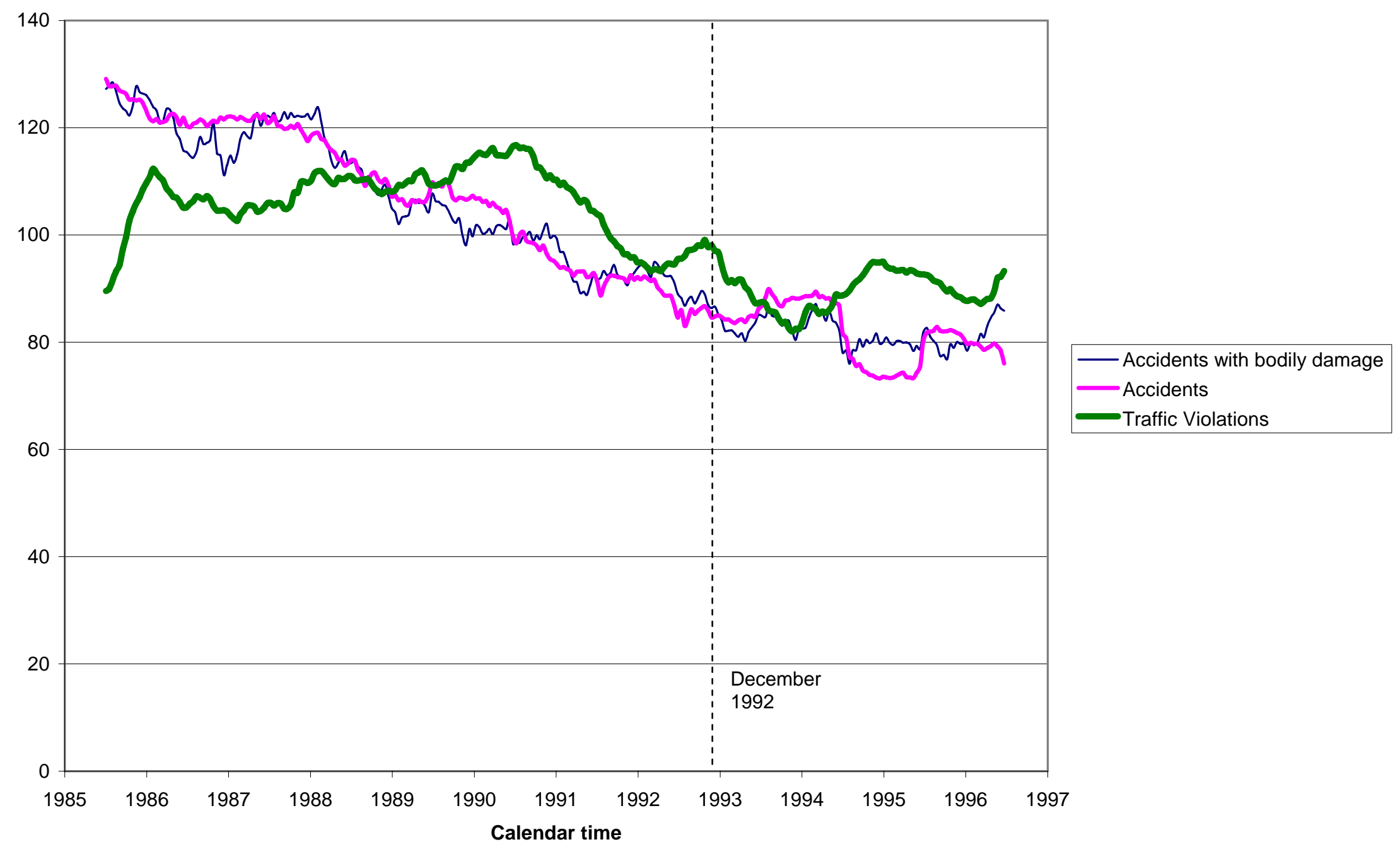


Figure 2.-- Expected variation of the optimal disutility after a traffic offense,

as a function of the accumulated demerit points and time

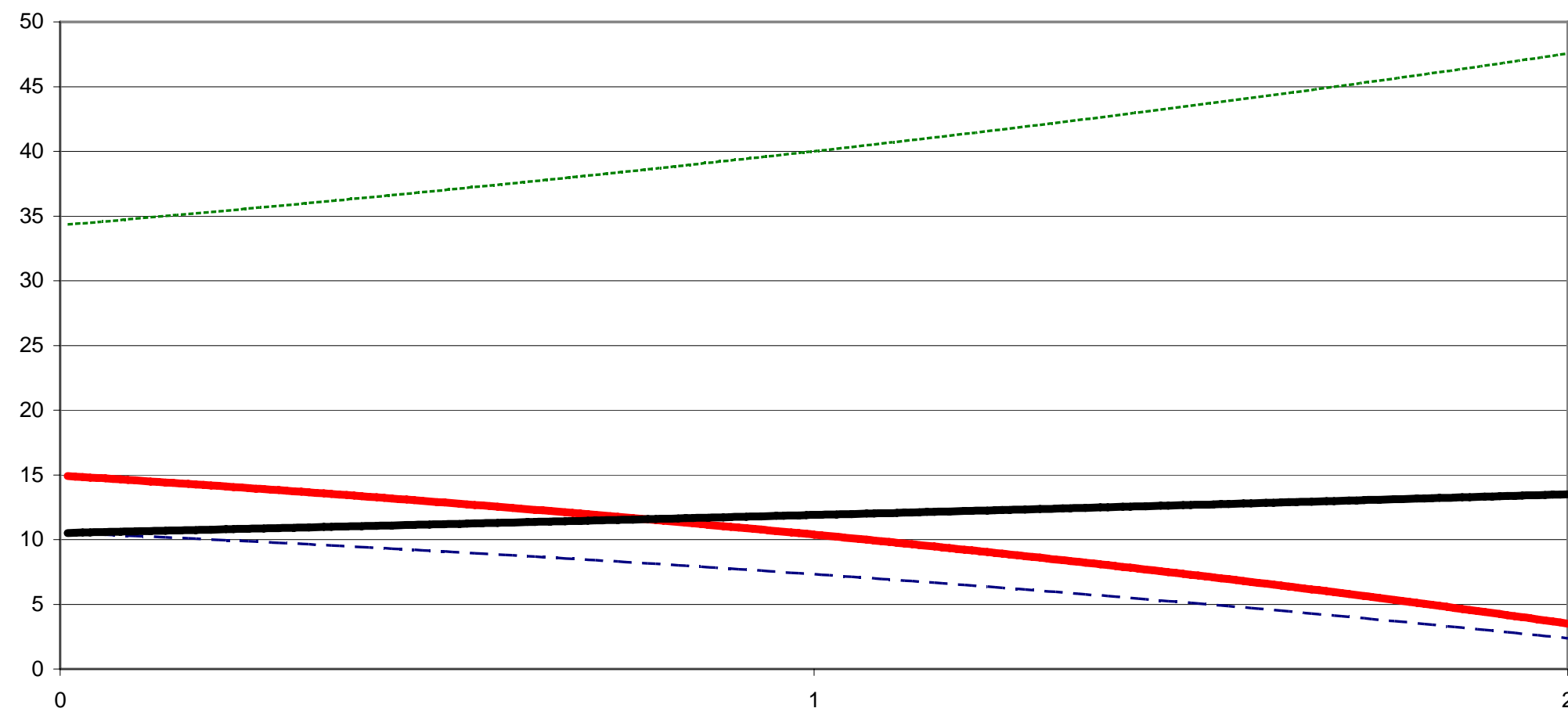

$\begin{array}{ll}-\ldots- & \Delta v_{1} \\ \cdots-. & \Delta v_{2} \\ & \Delta v_{4} \\ & \Delta \text { average }\end{array}$

Time elapsed since the last contract birthday (years) 
Figure 3. Baseline hazard functions for traffic violation risk, stratification by accumulated demerit points (cdp) in the last two years (strata cdp=0 and cdp>0)

One month moving average, vertical unit=initial value for the stratum defined by $c d p>0$

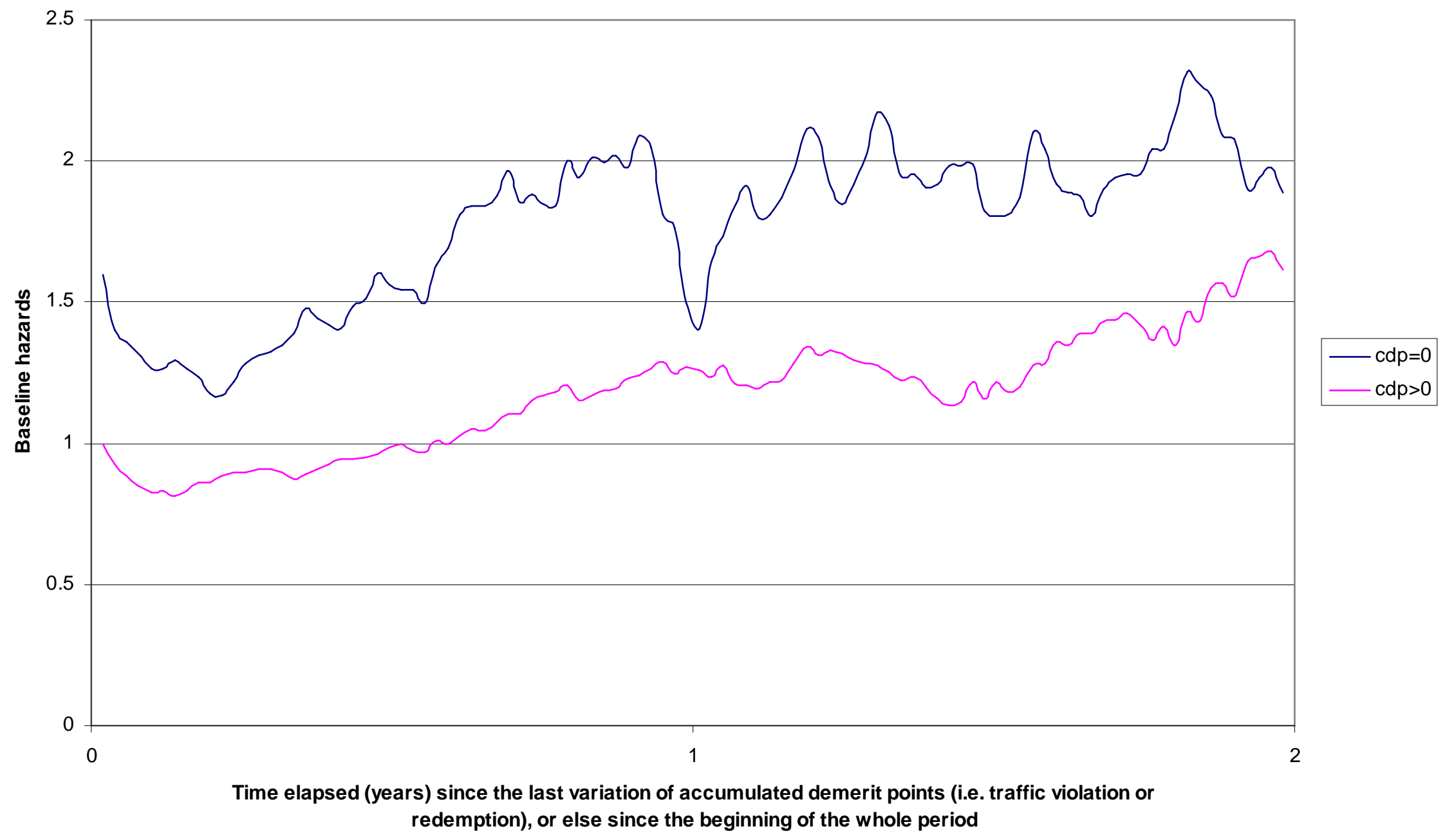




\section{References}

[1] Abbring, Jaap, Pierre-André Chiappori, and Jean Pinquet, "Moral Hazard and Dynamic Insurance Data," Journal of the European Economic Association 1 (2003), 767-820.

[2] Blomquist Glenn C., The Regulation of Motor Vehicle and Traffic Safety (Boston, Kluwer Academic Publishers, 1988).

[3] Boyer, Marcel and Georges Dionne, "The Economics of Road Safety," Transportation Research, 21B (5) (1987), 413-431.

[4] Boyer, Marcel and Georges Dionne, "An Empirical Analysis of Moral Hazard and Experience Rating," The Review of Economics and Statistics 71 (1989), 128-134.

[5] Bourgeon, Jean-Marc and Pierre Picard, "Point-Record Driving License and Road Safety: An Economic Approach," Journal of Public Economics 91 (2007), 235-258.

[6] Bühlmann, Hans, "Experience Rating and Credibility," ASTIN Bulletin 4, (1967), 199-207.

[7] Chiappori, Pierre-André, Ines Macho, Patrick Rey, and Bernard Salanié, "Repeated Moral Hazard: The Role of Memory, Commitment, and the Access to Credit Markets," European Economic Review 38 (1994), 15271553.

[8] Chiappori, Pierre-André and Bernard Salanié, "Testing for Asymmetric Information in Insurance Markets," Journal of Political Economy 108 (2000), 56-78.

[9] Cohen, Alma, "Asymmetric Information and Learning: Evidence from the Automobile Insurance Market," The Review of Economics and Statistics 87, 2 (2005), 197-207.

[10] Cox, David R., "Regression Models and Life Tables," Journal of the Royal Statistical Society, Series B, 34 (1972), 187-220. 
[11] Dionne, Georges and Pierre Lasserre, "Adverse Selection, Repeated Insurance Contracts and Announcement Strategy," Review of Economic Studies 70 (1985), 719-723.

[12] Dionne, Georges and Pierre Saint-Michel, "Workers' Compensation and Moral Hazard," The Review of Economics and Statistics 73 (1991), 236244.

[13] Dionne, Georges and Charles Vanasse, "A Generalization of Automobile Insurance Rating Models: The Negative Binomial Distribution with a Regression Component," ASTIN Bulletin 19 (1989), 199-212.

[14] Dionne, Georges, Christian Gouriéroux, and Charles Vanasse, "Testing for Evidence of Adverse Selection in the Automobile Insurance Market: A Comment," Journal of Political Economy 109 (2001), 444-453.

[15] Dionne, Georges, Mathieu Maurice, Jean Pinquet, and Charles Vanasse, "The Role of Memory in Long-Term Contracting with Moral Hazard: Empirical Evidence in Automobile Insurance," Working paper 01-05, HEC Montréal (2001). URL: http://neumann.hec.ca/gestiondesrisques/0105.pdf

[16] Doyle, Joseph J., "Health Insurance, Treatment and Outcomes: Using Auto Accidents as Health Shocks," The Review of Economics and Statistics 87, 2 (2005), 256-270.

[17] Finkelstein, Amy and Kathleen Mac Garry, "Multiple Dimensions of Private Information: Evidence from the Long-Term Care Insurance Market," American Economic Review 96 (2006), 938-958.

[18] Graham John D. and Steven Garber, "Evaluating the Effects of Automobile Safety Regulation," Journal of Economic Policy and Management 3, 2 (1984), 206-224.

[19] Haddon, William Jr., "The Changing Approach to the Epidemiology, Prevention, and Amelioration of Trauma: The Transition of Approaches Etiologically Rather than Descriptively Based," American Journal of Public Health 58 (1968), 1431-1438. 
[20] Landes, Elisabeth M. "Insurance, Liability, and Accidents: A Theoretical and Empirical Investigation of the Effect of No-fault Accidents," Journal of Law and Economics 25 (1982), 49-65.

[21] Murray, Christopher J.L., and Alan D. Lopez, "Alternative Projections of Mortality and Disability by Cause 1990-2020: Global Burden of Disease Study," The Lancet 349 (1997), 1498-1504.

[22] OECD International Road Traffic and Accident Data Base (2005). URL: http://cemt.org/IRTAD/.

[23] Peltzman, Sam, "The Effects of Automobile Regulation," Journal of Political Economy 83 (1975), 677-725.

[24] Pinquet, Jean, Montserrat Guillén, and Catalina Bolancé, "Allowance for the Age of Claims in Bonus-Malus Systems," ASTIN Bulletin 2, 31 (2001), 337-348.

[25] Puelz, Robert and Arthur Snow, "Evidence on Adverse Selection: Equilibrium Signaling and Cross-Subsidization in the Insurance Market," Journal of Political Economy 102 (1994), 236-257.

[26] Rockafellar, Ralph T., Convex Analysis (Princeton University Press, 1996).

[27] Rothschild, Michael, and Joseph Stiglitz "Equilibrium in Competitive Insurance Markets: An Essay on the Economics of Imperfect Information," The Quarterly Journal of Economics 90 (1976), 629-650.

[28] Shavell, Steven, "On Moral Hazard and Insurance," The Quarterly Journal of Economics 92 (1979), 541-562.

[29] Shavell, Steven, "The Optimal Use of Nonmonetary Sanctions as a Deterrent," American Economic Review 77 (1987), 584- 592.

[30] Sloan, Frank A., Bridget A. Reilly, and Christoph Schenzler, "Effects of Tort Liability and Insurance on Heavy Drinking and Driving," Journal of Law and Economics, 38 (1995), 49-77. 
[31] Viscusi, Kip W., "The Value of Risks to Life and Health," Journal of Economic Literature, 31 (1993), 1912-1946.

[32] WHO (World Health Organization), World Report on Road Traffic Injury Prevention (2004). WHO Press, Geneva. 


\section{A Appendix}

\section{A.1 Incentive effects of point-record driving licenses: Model without redemption}

Let us first give the main properties of the function

$$
\lambda_{*}: \Delta u \rightarrow \min _{e \geq 0} e+[\lambda(e) \times \Delta u]=\min _{e \geq 0} h(\Delta u, e),
$$

with $\lambda$ a positive, decreasing and strictly convex hazard function. The related optimal effort level is equal to

$$
\begin{gathered}
e_{\text {opt }}(\Delta u)=\arg \min _{e \geq 0} h(\Delta u, e) \Rightarrow \\
e_{\text {opt }}(\Delta u)=0 \text { if } \Delta u \leq \frac{-1}{\lambda^{\prime}(0)} ; e_{\text {opt }}(\Delta u)=\left(\lambda^{\prime}\right)^{-1}\left(\frac{-1}{\Delta u}\right) \text { if } \Delta u \geq \frac{-1}{\lambda^{\prime}(0)} .
\end{gathered}
$$

Hence the dual function $\lambda_{*}$ is defined on the real line as the optimal effort. From the last equation, we obtain

$$
\Delta u \leq \frac{-1}{\lambda^{\prime}(0)} \Rightarrow \lambda_{*}(\Delta u)=\lambda(0) \times \Delta u,
$$

and the dual function is linear in the neighborhood of 0 , which corresponds to no effort. The dual function $\lambda_{*}$ is strictly increasing since $\lambda$ is strictly positive. If $\Delta u \geq 0$, we have that:

$\lambda_{*}(\Delta u)=h\left(\Delta u, e_{\text {opt }}(\Delta u)\right) \geq e_{\text {opt }}(\Delta u) \Rightarrow \lim _{\Delta u \rightarrow+\infty} \lambda_{*}(\Delta u) \geq \lim _{\Delta u \rightarrow+\infty} e_{\text {opt }}(\Delta u)=+\infty$.

Hence $\lambda_{*}$ is an increasing homeomorphism on the real line.

The dual of a convex function is concave. This can be proved with geometrical arguments (see Rockafellar (1996)), or by the envelope theorem. We have

$$
h_{\Delta u}^{\prime}(\Delta u, e)=\lambda(e) \Rightarrow \lambda_{*}^{\prime}(\Delta u)=h_{\Delta u}^{\prime}\left(\Delta u, e_{o p t}(\Delta u)\right)=\lambda\left(e_{o p t}(\Delta u)\right) .
$$

Hence $\lambda_{*}$ is concave from the assumptions on $\lambda$ and from the properties of $e_{\text {opt }}$. We give a proof of the increasing property of the optimal effort level as a function of accumulated demerit points. From equation (1), we obtain

$$
u_{n}-u_{n+1}=\lambda_{*}^{-1}\left(r\left(u_{\max }-u_{n}\right)\right), u_{\max }=\frac{d_{u}}{r}(0 \leq n<N) .
$$


The sequence $\left(u_{n}\right)_{0 \leq n \leq N}$ is decreasing since we have $u_{\max } \geq u_{n}$. Plugging this result into the last equation implies that the sequence $\left(u_{n}-u_{n+1}\right)_{0 \leq n<N}$ is increasing. The optimal effort level is denoted as $e_{n}$, and expressed as

$$
e_{n}=\arg \min _{e \geq 0} e+\left[\lambda(e) \times\left(u_{n}-u_{n+1}\right)\right]=e_{o p t}\left(u_{n}-u_{n+1}\right),
$$

for $0 \leq n<N$, where $e_{o p t}$ is defined from (11). As $e_{o p t}$ is an increasing function, the optimal effort is an increasing function of the number of demerit points for any given value of the license suspension threshold.

Let us prove condition (4). From (14) and (12), we obtain

$$
e_{n}>0 \Leftrightarrow u_{n}-u_{n+1}=\frac{d_{u}-r u_{n}}{\lambda(0)}>\frac{-1}{\lambda^{\prime}(0)}=\underline{\Delta u} .
$$

If fines are included in the incentives, $u_{n+1}$ is replaced by $u_{n+1}-\overline{f a}$ in equation (1), which leads to the recurrence equation (see Figure 4)

$$
\begin{gathered}
d_{u}-r u_{n}=\lambda_{*}\left(u_{n}-u_{n+1}+\overline{f a}\right) \\
\Leftrightarrow u_{n+1}=u_{n}+\overline{f a}-\lambda_{*}^{-1}\left(d_{u}-r u_{n}\right)=g\left(u_{n}\right) .
\end{gathered}
$$

The fixed point of $g$ is the lifetime driving utility if fines were the only incentive scheme, i.e.

$$
\widetilde{u}_{\max }=\frac{d_{u}-\lambda_{*}(\overline{f a})}{r} .
$$

We of course assume that $d_{u}>\lambda_{*}(\overline{f a})$, i.e. $\widetilde{u}_{\max }>0$. If the two incentives are mixed, we have $u_{n} \leq \widetilde{u}_{\max }$ and we deduce from (16) the properties of utilities and of optimal effort levels as functions of $n$ that we obtained in the first place. Besides, we have

$$
e_{n}>0, \forall n, \Leftrightarrow \overline{f a}+u_{n}-u_{n+1}>\underline{\Delta u}, \forall n
$$

This condition is fulfilled if

$$
\overline{f a}>\underline{\Delta u}=-1 / \lambda^{\prime}(0),
$$

in which case the incentives are effective at every level. 
Notice that in this setting the optimal effort depends on the lifetime utility but not on the fines. Indeed, optimal effort depends on the argument of $\lambda_{*}$. From equation (16), this argument is equal to:

$$
u_{n}-u_{n+1}+\overline{f a}=\lambda_{*}^{-1}\left(d_{u}-r u_{n}\right) .
$$

Let us prove that optimal effort increases with the average fine for any given value of $n$ and $N$. Let us denote as $u_{n}^{j}$ the lifetime utility linked to an average fine $\overline{f a}^{j}(j=1,2)$. The recurrence equation is

$$
u_{n+1}^{j}=g_{j}\left(u_{n}^{j}\right), g_{j}(u)=f(u)+\overline{f a}^{j} .
$$

The function $f$ refers to the recurrence equation on utilities with the pointrecord driving license alone (see Figure 4). From equations (1) and (3), the $u_{n}^{j}$ are the solutions of the equations

$$
g_{j}^{\circ N}\left(u_{0}^{j}\right)-\beta u_{0}^{j}=0 ; g_{j}^{\circ N-n}\left(u_{n}^{j}\right)-\beta u_{0}^{j}=0 .
$$

We denote $g_{j} \circ \ldots \circ g_{j}$ as $g_{j}^{\circ n}$. Suppose that $\overline{f a}^{2}>\overline{f a}^{1}:$ as $g_{2}>g_{1}$, we have $g_{2}^{\circ N}\left(u_{0}^{1}\right)-\beta u_{0}^{1}>0$, which entails $u_{0}^{2}<u_{0}^{1}$ since the function $u \rightarrow g_{2}^{\circ N}(u)-\beta u$ is increasing (see Figure 4a). Indeed, we have $\beta<1$ and $g_{2}^{\prime}>1$. As $u_{N}^{j}=$ $\beta u_{0}^{j}(j=1,2)$, the inequality also holds for the terminal values of the utilities. As $g_{2}>g_{1}$ and $g_{2}^{\circ N-n}$ is increasing, equation (17) implies that the solution $u_{*}$ of the equation $g_{2}^{\circ N-n}\left(u_{*}\right)-\beta u_{0}^{1}=0$ is lower than $u_{n}^{1}$. As $u_{0}^{2}<u_{0}^{1}$, we obtain $u_{n}^{2}<u_{*}$ from the increasing property of $g_{2}^{\circ N-n}$. Hence, we have that $u_{n}^{2}<u_{n}^{1}$, and the lifetime utility as well as the optimal effort level decrease with the average fine for any given value of $n$ and $N$. This proof is summarized graphically in Figure $4 \mathrm{~b}$.

\section{A.2 Incentive effects of point-record driving licenses: Mod- els with redemption}

We derive below the incentive properties of the Type I redeeming systems presented in Section 4.3.

The expected utility is denoted as $u_{n}(t)$, where $t(0 \leq t \leq T)$ is the seniority of the last convicted traffic violation. The expected utility for $n=0$ does not 
depend on time, and is denoted as $u_{0}$. All the demerit points are redeemed if $t=T$, and we have $u_{n}(T)=u_{0}$ for $n=1, \ldots, N-1$. With the assumptions and notations of Section 4.2, the Bellman equation is

$$
\begin{gathered}
u_{n}^{\prime}(t)=\left(r u_{n}(t)-d_{u}\right)+\lambda_{*}\left(u_{n}(t)-u_{n+1}(0)\right)(0 \leq n<N) \\
\Leftrightarrow u_{n}^{\prime}=f_{u_{n+1}(0)}\left(u_{n}\right), f_{v}(u)=\left(r u-d_{u}\right)+\lambda_{*}(u-v) .
\end{gathered}
$$

Hence $u_{n}(t)$ is defined implicitly by the equation

$$
\int_{u_{n}(t)}^{u_{n}(T)=u_{0}} \frac{d u}{f_{u_{n+1}(0)}(u)}=T-t, \forall t \in[0, T] .
$$

The functions $f_{v}$ are strictly increasing and the integral of $1 / f_{v}$ diverges in the neighborhood of the value which nullifies $f_{v}$ because we have

$$
r<f_{v}^{\prime}(u) \leq r+\lambda(0) \forall u, v \text {. }
$$

Hence $u_{n+1}(0)$ is defined from $u_{n}(0)$ from equation (19) with $t=0$, which implies that

$$
f_{u_{n+1}(0)}\left(u_{n}(0)\right)>0 .
$$

This condition holds if $f_{v}\left(u_{n}(0)\right)>0$ for positive values of $v$, which amounts to

$$
u_{n}(0)>\underline{u}, \text { with } f_{0}(\underline{u})=\left(r \underline{u}-d_{u}\right)+\lambda_{*}(\underline{u})=0 .
$$

Then

$$
f_{u_{n+1}(0)}(u)>0 \forall u \in\left[u_{n}(0), u_{n}(T)=u_{0}\right]
$$

and $u_{n}$ is strictly increasing on $[0, T]$ from (18).

A result with an obvious economic interpretation is that the sequence $\left(u_{n}(0)\right)_{n=0, \ldots, N}$ is decreasing. Indeed, we have

$$
f_{u_{n+1}(0)}\left(u_{n}(0)\right)>0 \Leftrightarrow u_{n}(0)-u_{n+1}(0)>\lambda_{*}^{-1}\left(d_{u}-r u_{n}(0)\right)>0 .
$$

Let us prove now the concavity of the sequence $\left(u_{n}(0)\right)_{n=0, \ldots, N}$, which means that the sequence $\left(u_{n}(0)-u_{n+1}(0)\right)_{n=0, \ldots, N}$ is increasing. The recurrence equation

$$
u_{n+1}(0)=w\left(u_{n}(0)\right), \text { with } \int_{v}^{u_{0}} \frac{d u}{\left(r u-d_{u}\right)+\lambda_{*}(u-w(v))}=T
$$


follows from (19) with $t=0$. Consider $v_{0}, v_{1}$ with $\underline{u}<v_{0}<v_{1}<d_{u} / r$. We have

$\int_{v_{1}}^{u_{0}} \frac{d u}{\left(r u-d_{u}\right)+\lambda_{*}\left(u-w\left(v_{1}\right)\right)}=T ; \int_{v_{0}}^{u_{0}} \frac{d u}{\left(r u-d_{u}\right)+\lambda_{*}\left(u-w\left(v_{1}\right)+v_{1}-v_{0}\right)}>T$.

The first equality results from (21). The second integrand is greater than the first one if the comparison starts from the lower bound of the integral, and the wider range of the second integration reinforces the inequality. As these integrals increase with $w$, we have that

$$
v_{0}<v_{1} \Rightarrow w\left(v_{1}\right)+v_{0}-v_{1}>w\left(v_{0}\right) .
$$

Hence the function $v \rightarrow v-w(v)$ is decreasing. We obtain the desired result with $v_{0}=u_{n+1}(0)$ and $v_{1}=u_{n}(0)$.

We can then prove the results given in Section 4.3 on the optimal effort level, which we denote as $e_{n}(t)$. We have

$$
e_{n}(t)=e_{\text {opt }}\left(u_{n}(t)-u_{n+1}(0)\right) \text {, }
$$

where $e_{\text {opt }}$ is the increasing function defined in equation (11). Since the functions $u_{n}$ are strictly increasing on $[0, T]$, equation (22) implies the optimal effort level increases with time for a given number of demerit points. From the definition of $e_{\text {opt }}$, the optimal effort is strictly increasing if it is greater than zero.

If the duration between demerit points $n$ and $n+1$ is equal to $t$, the transition between the optimal effort levels is

$$
e_{n}(t)=e_{\text {opt }}\left(u_{n}(t)-u_{n+1}(0)\right) \rightarrow e_{n+1}(0)=e_{\text {opt }}\left(u_{n+1}(0)-u_{n+2}(0)\right) \text {. }
$$

If the last traffic violation immediately follows another one, the variation is positive because of the concavity of the sequence $\left(u_{n}(0)\right)_{n=0, \ldots, N}$. Since $u_{n}$ is increasing, the variation of optimal effort after a convicted traffic violation decreases with the duration between the two last offenses.

The following picture gives an example where

$$
u_{n}(t)-u_{n+1}(0)>u_{n+1}(0)-u_{n+2}(0),
$$

which implies a drop of the effort level and an increase in risk if the driver is convicted with a supplementary demerit point. This result is in contrast with 
what is expected with a Type II redeeming mechanism.

\section{Insert Figure 5 about here}

Lastly, the optimal effort after a redemption of all the demerit points is equal to $e_{0}=e_{\text {opt }}\left(u_{0}-u_{1}(0)\right)$. This value is lower or equal to any optimal effort level. Indeed, we have

$$
u_{0}-u_{1}(0) \leq u_{n}(0)-u_{n+1}(0) \leq u_{n}(t)-u_{n+1}(0)
$$

from the properties proved on the utility functions.

Let us now consider a redeeming system of Type II. The state variables are the seniorities of each non redeemed traffic offense, if any. Let us denote these variables as

$$
S=\left(t_{1}, \ldots, t_{n}\right), \quad 0 \leq t_{1}<\ldots<t_{n}<T .
$$

The corresponding lifetime utility and optimal effort are denoted as $u(S)$ and $e(S)$. Then the states reached without traffic offense before the next redemption are

$$
S_{t}=\left(t_{1}+t, \ldots, t_{n}+t\right), 0 \leq t<T-t_{n} .
$$

We denote the state reached from $S$ after an additional traffic offense (if $n<N$ ) as

$$
\left(0, t_{1}, \ldots, t_{n}\right)=T R(S)
$$

The Bellman equation on lifetime utility can be written as follows

$$
d_{u}-r u(S)+\left(\frac{d}{d t}\left[u\left(S_{t}\right)\right]\right)_{t=0^{+}}=\lambda_{*}(u(S)-u(T R(S))) .
$$

Hence we have that

$$
e(S)=e_{\text {opt }}(u(S)-u(T R(S)))
$$

Results similar to those derived for the Type I redeeming system do not seem simple to obtain from the Bellman equation. For instance the monotonicity of the map $t \rightarrow e\left(S_{t}\right)$ seems questionable. The result which follows suggests that this map should globally be decreasing. 
Let us prove the continuity of optimal effort after a redemption in a Type II system. Since the lifetime utility is continuous after a redemption, we have the following result:

$$
n \geq 1: \lim _{t \rightarrow\left(T-t_{n}\right)^{-}} u\left(S_{t}\right)=u\left(S^{R}\right), S^{R}=\left(t_{1}+T-t_{n}, \ldots, t_{n-1}+T-t_{n}\right) .
$$

The state $S^{R}$ is reached from $S$ if there is no traffic offense before the first redemption. Then it is easily seen that

$$
\lim _{t \rightarrow\left(T-t_{n}\right)^{-}} u\left[T R\left(S_{t}\right)\right]=u\left[T R\left(S^{R}\right)\right]=u\left(0, t_{1}+T-t_{n}, \ldots, t_{n-1}+T-t_{n}\right) .
$$

This means that the left continuity at $T-t_{n}$ of the map $t \rightarrow u\left(S_{t}\right)$ also holds for the map $t \rightarrow u\left[T R\left(S_{t}\right)\right]$, which is associated with the states reached after an additional traffic offense. The reason is that redemption of past offenses occurs regardless of the future individual history.

From the three last equations, we obtain

$$
\lim _{t \rightarrow\left(T-t_{n}\right)^{-}} e\left(S_{t}\right)=e\left(S^{R}\right)
$$

and the continuity property of the optimal effort level. Since we expect a global increasing link between optimal effort and the accumulated demerit points, the time-effect should globally be decreasing in order to fulfill this continuity property.

\section{A.3 Incentive effects of the experience rating system}

Let us first prove the Bellman equation on the expected disutility function given in (7), including an average fine of $f a_{j}$ for a $j$ demerit point traffic violation. The optimal disutility function is obtained from the program

$$
\begin{gathered}
v_{n}(t)=\min _{e \geq 0} e d t+\left(\exp (-r d t) \times(1-\lambda(e) d t) \times v_{n}(t+d t)\right) \\
+\left(\exp (-r d t) \times\left[\sum_{j / f_{j}>0} f_{j} \lambda(e) d t \times\left[v_{\min (n+j, N)}(t+d t)+f a_{j}\right]\right]\right)+o(d t),
\end{gathered}
$$


which leads to

$$
0=v_{n}^{\prime}(t)+\lambda_{*}\left(\overline{f a}+\left(\sum_{j / f_{j}>0} f_{j} v_{\min (n+j, N)}(t)\right)-v_{n}(t)\right)-r v_{n}(t),
$$

with $\overline{f a}=\sum_{j / f_{j}>0} f_{j} \times f a_{j}$ the average fine. Then we obtain (7) with the average fine included in the argument of the dual function.

\section{A.4 Holistic incentive models and overall comparisons}

\section{A.4.1 Holistic incentive model}

The Bellman equation on a holistic incentive model can be written as follows

$$
d_{u}-r u(S)+\left(\frac{d}{d t}\left[u\left(S_{t}\right)\right]\right)_{t=0^{+}}=\lambda_{*}(\overline{f a}+u(S)-E[u(T R(S))]) .
$$

The state variables $S$ are the seniorities of each non redeemed traffic offense (if any), the related demerit points and the seniority of the last contract birthday. The related lifetime utility is $u(S)$. The state $S_{t}$ is reached from $S$ with an eventless history (no traffic offense, redemption or contract birthday) of duration $t$. The parameters $d_{u}$ and $\overline{f a}$ are the driving utility flow and the average fine, and $E[u(T R(S))]$ is the lifetime utility averaged with transition probabilities on the state(s) reached from $S$ after a traffic offense. Continuity equations on utility before and after a redemption or at a contract birthday (in the latter case, the increase in lifetime utility is equal to the disutility of the premium) and the equation linking the utility of a beginner and just after a license suspension define the solution together with equation (23).

\section{A.4.2 Elasticity between optimal frequency risk and the argument of $\lambda_{*}$ when the incentives are effective}

As a conclusion, let us derive the link given in Section 6.2 between the elasticity of the optimal frequency of traffic violations and the argument of $\lambda_{*}$, which determines the optimal effort level. We perform a local expansion around a value $\Delta u^{0}$ of the argument of $\lambda_{*}$, in a situation where the incentives are effective (i.e. $\left.\Delta u^{0}>\underline{\Delta u}=-1 / \lambda^{\prime}(0)\right)$. If we write

$$
e^{0}=e_{o p t}\left(\Delta u^{0}\right), e^{0}+d e=e_{o p t}\left(\Delta u^{0}+d \Delta u\right)
$$


the equations

$$
1+\lambda^{\prime}\left(e^{0}\right) \Delta u^{0}=0 ; 1+\left[\lambda^{\prime}\left(e^{0}+d e\right)\left(\Delta u^{0}+d \Delta u\right)\right]=0
$$

lead to

$$
d e=\frac{-\lambda^{\prime}\left(e^{0}\right)}{\lambda^{\prime \prime}\left(e^{0}\right) \Delta u^{0}} d \Delta u+o(d \Delta u),
$$

and to

$$
\frac{d \lambda}{\lambda\left(e^{0}\right)}=\frac{\lambda^{\prime}\left(e^{0}\right)}{\lambda\left(e^{0}\right)} d e=\frac{\left[-\lambda^{\prime}\left(e^{0}\right)\right]^{2}}{\lambda\left(e^{0}\right) \times \lambda^{\prime \prime}\left(e^{0}\right)} \times \frac{d \Delta u}{\Delta u^{0}} .
$$

Hence the aforementioned elasticity is equal to $\left(\lambda^{\prime}\right)^{2} / \lambda \lambda^{\prime \prime}$. Now we have that

$$
(\log \lambda)^{\prime \prime}=\frac{\lambda^{\prime \prime}}{\lambda}-\left(\frac{\lambda^{\prime}}{\lambda}\right)^{2}=\frac{\lambda^{\prime \prime}}{\lambda}\left(1+\frac{\left(\lambda^{\prime}\right)^{2}}{\lambda \lambda^{\prime \prime}}\right) .
$$

Then the conclusions given in Section 4.2 are easily obtained.

\section{A.5 Actuarial predictors with dynamic random effects}

Actuarial predictors are used as offset variables in the duration models estimated in Section 6.1. The predictors which follow generalize the basic formula given in (9) for constant random effects. The seniority of past traffic violations supplements their number and risk exposure, already included in the basic predictor. The bonus-malus coefficient $B M_{i}^{j}(m)$ given in (10) is obtained from an affine probabilistic regression of a multiplicative random effect $\varepsilon_{i, m}^{j}$ related to driver $i$, month $m$ and type $j$ event with respect to the number of traffic violations recorded for the driver for each past month, and denoted as $N_{i, m_{1}}^{1}\left(m_{1}<m\right)$. With the assumption $E\left(\varepsilon_{i, m}^{j}\right)=1$, the predictor is given by

$$
B M_{i}^{j}(m)=1+{ }^{t} \widehat{\operatorname{Cov}}\left(S N_{i, m}^{1}, \varepsilon_{i, m}^{j}\right)\left[\widehat{V}\left(S N_{i, m}^{1}\right)\right]^{-1}\left(s n_{i, m}^{1}-\widehat{E}\left(S N_{i, m}^{1}\right)\right),
$$

where $S N_{i, m}^{1}=\underset{m_{1}<m}{v e c}\left(N_{i, m_{1}}^{1}\right)$ is the stacked vector of numbers of past traffic violations. The moments in the last expression are estimated from moments of the random effects derived from Table 2 (see Pinquet, Guillén, Bolancé (2001) for details). 
Figure 4

Recurrence equation on the lifetime utility function

Point-record driving license without fines: $u_{n+1}^{0}=f\left(u_{n}^{0}\right)$

Point-record driving license with fines: $u_{n+1}=g\left(u_{n}\right)$

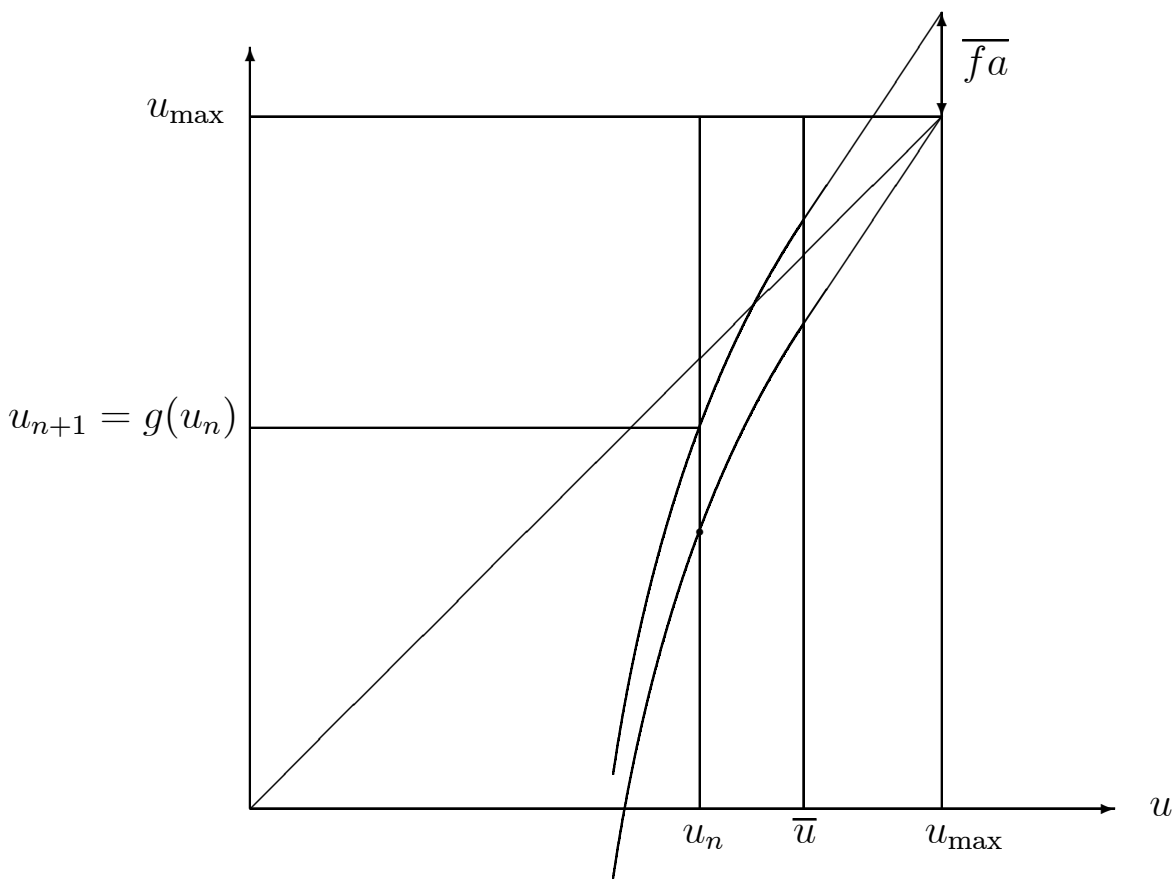

$$
f(u)=u-\lambda_{*}^{-1}\left(r\left(u_{\max }-u\right)\right), g(u)=f(u)+\overline{f a} .
$$

Effective incentives condition with and without fines

$$
e_{n}>0 \Leftrightarrow u_{n}<\bar{u}=u_{\max }\left(1+\frac{\lambda(0)}{\lambda^{\prime}(0) \times d_{u}}\right) .
$$


Figure 4a

Graphical proof for $u_{0}^{2}<u_{0}^{1}$.

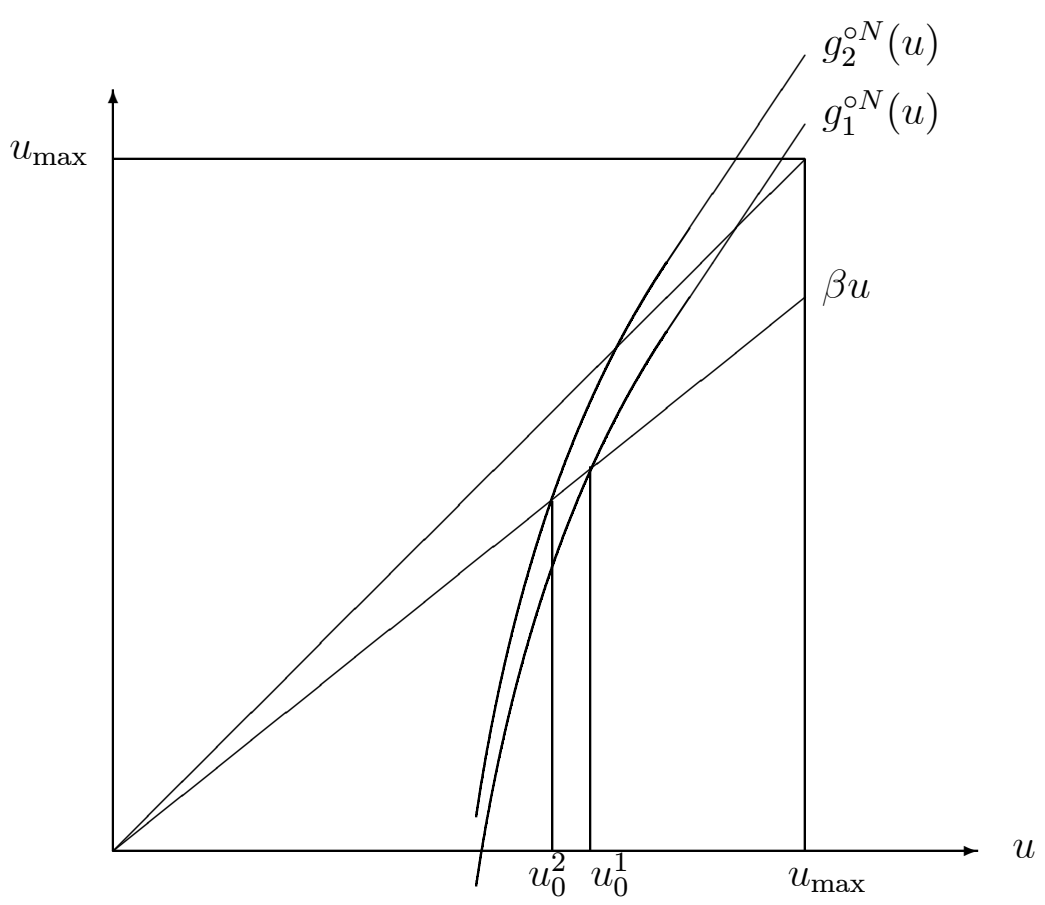


Figure 4b

Graphical proof for $u_{n}^{2}<u_{n}^{1}(N>n>0)$.

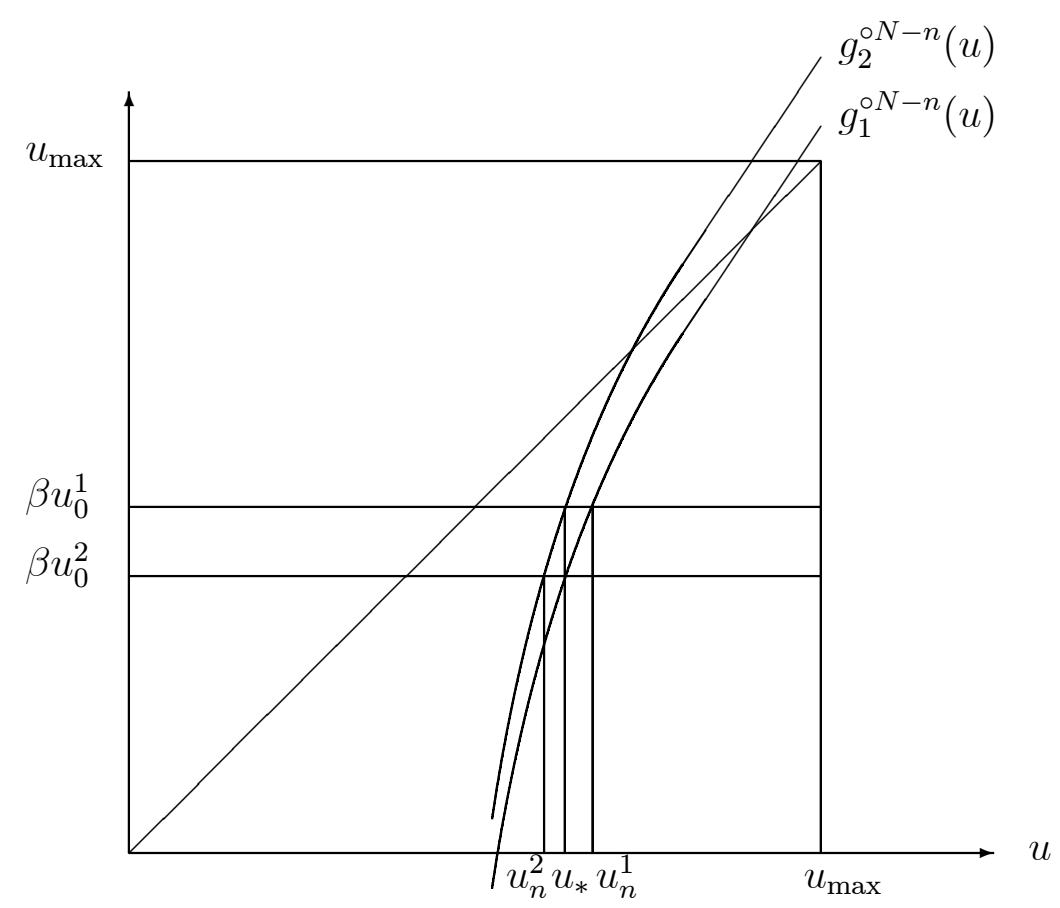


Figure 5: Utility functions and variation of the optimal effort level

Optimal effort decreases after a traffic violation in the state $(n, t)$ if and only if

$$
u_{n}(t)-u_{n+1}(0)>u_{n+1}(0)-u_{n+2}(0) \Longleftrightarrow t>t_{0} .
$$

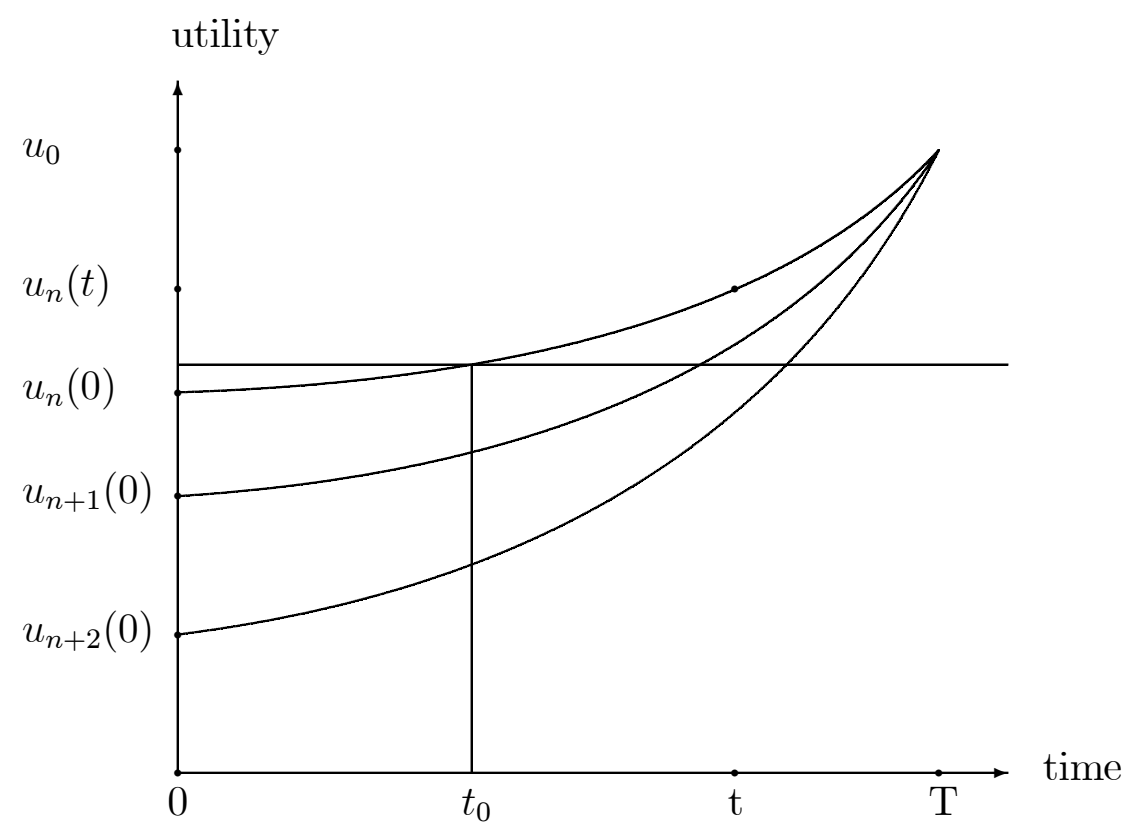

